\title{
Evaluation of the Surface Urban Energy and Water Balance Scheme (SUEWS) at a Dense Urban Site in Shanghai: Sensitivity to Anthropogenic Heat and Irrigation
}

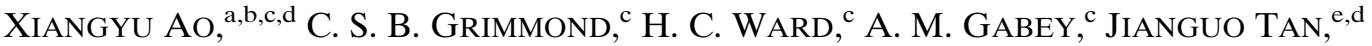

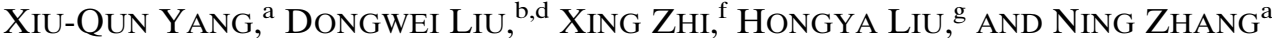 \\ ${ }^{a}$ School of Atmospheric Sciences, Nanjing University, Nanjing, China \\ ${ }^{\mathrm{b}}$ Shanghai Institute of Meteorological Science, Shanghai Meteorological Service, Shanghai, China \\ ${ }^{\mathrm{c}}$ Department of Meteorology, University of Reading, Reading, United Kingdom \\ ${ }^{\mathrm{d}}$ Shanghai Key Laboratory of Meteorology and Health, Shanghai, China \\ e Shanghai Climate Centre, Shanghai Meteorological Service, Shanghai, China \\ ${ }^{\mathrm{f}}$ Department of Science and Technology Development, Shanghai Meteorological Service, Shanghai, China \\ ${ }^{\mathrm{g}}$ Shanghai Central Meteorological Observatory, Shanghai, China
}

(Manuscript received 30 March 2018, in final form 17 October 2018)

\begin{abstract}
The Surface Urban Energy and Water Balance Scheme (SUEWS) is used to investigate the impact of anthropogenic heat flux $Q_{F}$ and irrigation on surface energy balance partitioning in a central business district of Shanghai. Diurnal profiles of $Q_{F}$ are carefully derived based on city-specific hourly electricity consumption data, hourly traffic data, and dynamic population density. The $Q_{F}$ is estimated to be largest in summer (mean daily peak $236 \mathrm{~W} \mathrm{~m}^{-2}$ ). When $Q_{F}$ is omitted, the SUEWS sensible heat flux $Q_{H}$ reproduces the observed diurnal pattern generally well, but the magnitude is underestimated compared to observations for all seasons. When $Q_{F}$ is included, the $Q_{H}$ estimates are improved in spring, summer, and autumn but are poorer in winter, indicating winter $Q_{F}$ is overestimated. Inclusion of $Q_{F}$ has little influence on the simulated latent heat flux $Q_{E}$ but improves the storage heat flux estimates except in winter. Irrigation, both amount and frequency, has a large impact on $Q_{E}$. When irrigation is not considered, the simulated $Q_{E}$ is underestimated for all seasons. The mean summer daytime $Q_{E}$ is largely overestimated compared to observations under continuous irrigation conditions. Model results are improved when irrigation occurs with a 3-day frequency, especially in summer. Results are consistent with observed monthly outdoor water use. This study highlights the importance of appropriately including $Q_{F}$ and irrigation in urban land surface models-terms not generally considered in many previous studies.
\end{abstract}

\section{Introduction}

China has experienced unprecedented urban growth in recent decades, with the fraction of city dwellers increasing from $17.9 \%$ to $55.6 \%$ between 1978 and 2015 (United Nations 2017). If these rates continue, the urban population will exceed 1 billion in China within the next two decades. This rapid urbanization has brought significant economic growth, while at the same time exposing people to urban climatic and environmental risks, such as persistent heat waves, flooding, and air pollution (Jiang et al. 2015; Li et al. 2015; Zhong et al. 2015; Ding et al. 2016; Xu et al. 2016; Yang et al. 2017).

Corresponding authors: Ning Zhang, ningzhang@nju.edu.cn; Xiu-Qun Yang, xqyang@nju.edu.cn
Cities are well known to have distinct climatic conditions that result from the alteration of the urban surfaceatmosphere energy and water exchanges compared to surrounding rural surfaces (Roth et al. 2017; Zou et al. 2017). Absorption and trapping of incoming shortwave radiation by deep urban canyons leads to greater absorption of energy by the surface and a smaller surface albedo than surrounding environments (Oke 1988; Christen and Vogt 2004; Guo et al. 2016). More heat is stored in high thermal admittance building walls during the daytime, which is then released at night, creating the distinct nocturnal urban heat island (UHI; Grimmond and Oke 1999; Roberts et al. 2006; Wu and Yang 2013; Kotthaus and Grimmond 2014). The replacement of natural vegetative surfaces with impervious paved and built surfaces leads to less energy partitioning into 
evapotranspiration and reduces the associated cooling effect (Grimmond and Oke 1986; Nakayoshi et al. 2009; Ward and Grimmond 2017). Urban runoff is usually significantly enhanced following rainfall, given the abundance of paved and built surfaces. This rapid rate of runoff also removes a large amount of surface water suppressing evaporation rates (Ragab et al. 2003). Human activities, related to building heating and cooling, vehicles, and human metabolism (Sailor 2011; Lindberg et al. 2013), release extra anthropogenic heat into the urban environment.

Urban land surface models (ULSMs) can be effective tools to investigate and quantify these surfaceatmosphere exchanges and interactions to yield insight into the different factors influencing the climate of a city. Numerous ULSMs have been developed over the last few decades, with varying degrees of complexity (e.g., Kusaka et al. 2001; Oleson et al. 2008; Järvi et al. 2011; Chen et al. 2011; Masson et al. 2013; Miao and Chen 2014). Grimmond et al. (2010, 2011), in the first international comparison of ULSMs, found no single model performs best or worst for all fluxes. Considering the implications of this study, Best and Grimmond (2016b) concluded that attention needs to be directed to the modeling of the latent heat flux, inclusion (or not) of vegetation, and calculation of the anthropogenic heat flux by ULSMs. These elements are simulated poorly, yet are key factors impacting overall model performance. They are the focus of this paper.

ULSMs often simulate the latent heat flux separately for natural (vegetation or pervious) and built (road, walls, roof) surfaces, with no interaction between them. Furthermore, ULSMs rarely incorporate any detailed consideration of urban hydrological processes, such as drainage, interception, runoff, or irrigation. For example, the early version of the widely implemented singlelayer urban canopy model (SLUCM) system (Kusaka et al. 2001) uses a simplified hydrologic process in which evaporation only occurs after precipitation events, even though SLUCM implements a sophisticated representation of urban canopy geometry. Recently, enhanced hydrological processes including anthropogenic latent heat, urban irrigation, and urban oasis effects have been implemented into the SLUCM system (Miao and Chen 2014; Yang et al. 2015), which improves the model performance substantially especially for the latent heat flux.

Given the large fraction of impervious surfaces in urban areas, city drainage systems are designed to quickly remove runoff. In many settings this gives rise to a deficit of soil moisture in the urban landscape (Coutts et al. 2013) and irrigation is often needed to maintain vegetation health (Grimmond and Oke 1986;
Demuzere et al. 2014). This urban irrigation has been shown to be a critical component of the urban water balance, especially in arid and hot regions, and plays a key role in the energy partitioning between latent and sensible heat fluxes and the associated urban cooling efficiency. Vahmani and Hogue (2014, 2015) developed and assessed an irrigation scheme within the framework of the Noah-SLUCM system for the Los Angeles metropolitan area and demonstrated that appropriately incorporating urban irrigation can significantly improve model performance. However, the majority of ULSMs applications still ignore irrigation, especially in subtropical cities, which are considered to have plenty of rainfall to maintain a sufficient water supply. This, however, is not always the case, and with increased frequency of extreme heat waves the potential need for external water supply can be substantial in these cities.

The anthropogenic heat flux $Q_{F}$ also plays a critical role in ULSMs and has been the focus of significant attention (Grimmond 1992; Sailor and Lu 2004; Allen et al. 2011; Zhang et al. 2016; Best and Grimmond 2016a). The $Q_{F}$, the additional energy produced by human activities released into the environment, can be a significant component of the urban energy balance with distinct seasonal and diurnal variations. For example, the estimated daytime $Q_{F}$ in central Tokyo (Ichinose et al. 1999) exceeded $400 \mathrm{~W} \mathrm{~m}^{-2}$ at 1400 local standard time (LST) on average and reached $1590 \mathrm{~W} \mathrm{~m}^{-2}$ in winter (25-m resolution), enhancing the UHI by $1^{\circ}-$ $2.5^{\circ} \mathrm{C}$. The magnitude of $Q_{F}$ is scale and location dependent. Typically, it is highest in central urbanized areas and much less when averaged over the entire city. Incorporating $Q_{F}$ into mesoscale weather forecast models has been shown to have a significant impact on model predictions when city-specific $Q_{F}$ profiles and magnitudes are provided (Salamanca et al. 2014). However, such city-specific $Q_{F}$ diurnal profiles are often very difficult to obtain given the lack of detailed local energy consumption data. As a result, most urban modelers simply use a default fixed $Q_{F}$ diurnal profile (e.g., two diurnal peaks at 0800 and 1700 LST is the default in WRF-UCM), fixed values regardless of the city (e.g., Wang et al. 2015; L. Chen et al. 2016), or turn anthropogenic heating off (e.g., Zhang et al. 2010; Loridan et al. 2013; Wang et al. 2014; S. Zhong et al. 2017). This diversity of approaches has contributed to contradictory results on the impact of $Q_{F}$ on local climate. For example, two recent studies have shown inconsistent impacts of $Q_{F}$ with the WRF-UCM default $Q_{F}$ on precipitation: F. Chen et al. (2016) report it results in increases in precipitation, while Feng et al. (2012) report a decrease of precipitation in the same 
region (Hangzhou, China). Others, however, have made significant advances in this realm. Sailor et al. (2015) developed a national database of anthropogenic heat profiles for the United States and extended this, by simple adjustments, for a range of international megacities. Adopting a different approach, Nie et al. (2017) used WRF-building effect parameterization plus building energy model $(\mathrm{BEP}+\mathrm{BEM})$ to estimate spatially and diurnally varying $Q_{F}$ in Beijing. However, given the vast diversity of cities in China, there is an urgent need to develop datasets and models that simulate the spatial and temporal variability of $Q_{F}$ across cities.

The Surface Urban Energy and Water Balance Scheme (SUEWS) is a local-scale urban land surface model of moderate complexity (Järvi et al. 2011; Ward et al. 2016). SUEWS has the advantage that it simulates the urban surface energy balance in combination with the complete urban hydrological cycle, considering irrigation and runoff processes. The urban water balance interacts with the energy balance through evaporation $E$, as $Q_{E}=L_{V} E$, where $Q_{E}$ is the latent heat flux and $L_{V}$ is the latent heat of vaporization. Moreover, SUEWS requires only commonly available meteorological input data and detailed information about the urban surface. The urban surface is split into seven land cover types (buildings, paved surfaces, coniferous trees and shrubs, deciduous trees and shrubs, grass, bare soil, and water) with integrated urban vegetation effects, a previously highlighted key factor for improving the accuracy of ULSMs (Grimmond et al. 2010, 2011). These characteristics of SUEWS have enabled the model to be used widely as an effective tool for climate (water) sensitive urban design and urban climate disaster and mitigation strategy assessment (Mitchell et al. 2008; Järvi et al. 2017; Ward and Grimmond 2017; Ward et al. 2017; Rafael et al. 2017).

The SUEWS model was originally tested using data collected from a midlatitude suburb in Vancouver, Canada (Grimmond and Oke 1986, 1991; Loridan et al. 2011; Järvi et al. 2011). It has been evaluated extensively in North American and European cities and shown to produce realistic and robust results (Järvi et al. 2014; Alexander et al. 2015; Karsisto et al. 2016; Ward and Grimmond 2017; Kokkonen et al. 2018). However, evaluation of SUEWS in rapidly urbanizing subtropical (or tropical) cities is still lacking, with the exception of recent work in tropical Singapore (Demuzere et al. 2017). Given the vast diversity of climatic settings and urban geometrical structures [cf. local climate zones in Stewart and Oke (2012)] of different cities, further evaluation of the model in subtropical cities is of paramount importance. Shanghai, the largest subtropical city in China, characterized by numerous skyscrapers and dense urbanization, provides a test bed to evaluate SUEWS.

The objective of this study is to evaluate the performance of SUEWS in a central business site of Shanghai for one year using directly measured surface energy flux observations (Ao et al. 2016a,b). Special attention is directed to the impact of the seasonally varying diurnal profiles of $Q_{F}$ derived from city-scale annual energy consumption data, hourly electricity power load data, and traffic count data. The impact of urban irrigation on the simulation of latent heat flux (evaporation) is also addressed using the empirical irrigation scheme in SUEWS. This study provides insights into the performance of SUEWS and its potential to investigate strategies to mitigate urban heat stress and create resilient and sustainable urban environments.

\section{Methodology}

\section{a. Site and observations}

The evaluation of SUEWS uses data (December 2012-November 2013) observed over a dense urban site (XJH) in Shanghai, China (Fig. 1). The four components of net all-wave radiation, the turbulent sensible and latent heat fluxes, and basic meteorological variables (air temperature, relative humidity, and pressure) are directly measured at this site on a tall tower (full details are provided in Ao et al. 2016a,b). Precipitation is measured nearby ( $60 \mathrm{~m}$ away) with an automatic weather station (AWS).

Annual and seasonal performance of SUEWS is considered using carefully quality controlled data (see further details in Ao et al. 2016a,b). Data from sectors strongly influenced by a tall building $\left(210^{\circ}-247^{\circ}\right)$ and the tower itself $\left(320^{\circ}-337^{\circ}\right)$ are excluded. Wet conditions (within 1 day after rain) are excluded as rain drops on open-path sensors generate errors.

Surface cover parameters needed for SUEWS are retrieved from GIS data and a ground survey for a 500-m radius around the site. The Kljun et al. (2004) flux source area model suggests that the $80 \%$ source area extends to about $600 \mathrm{~m}$ from the site.

The four seasons of a year are defined based on the commonly used classification in China: winter [DecemberFebruary (DJF)], spring [March-May (MAM)], summer [June-August (JJA)], and autumn [September-November (SON)]. Local standard time is used (China does not use daylight saving time).

\section{b. Estimation of anthropogenic heat flux $Q_{F}$}

In SUEWS, the daily anthropogenic heat flux $Q_{F, S \text {,daily }}$ is calculated adopting the Sailor and Vasireddy (2006) based approach. This is a function of population density 

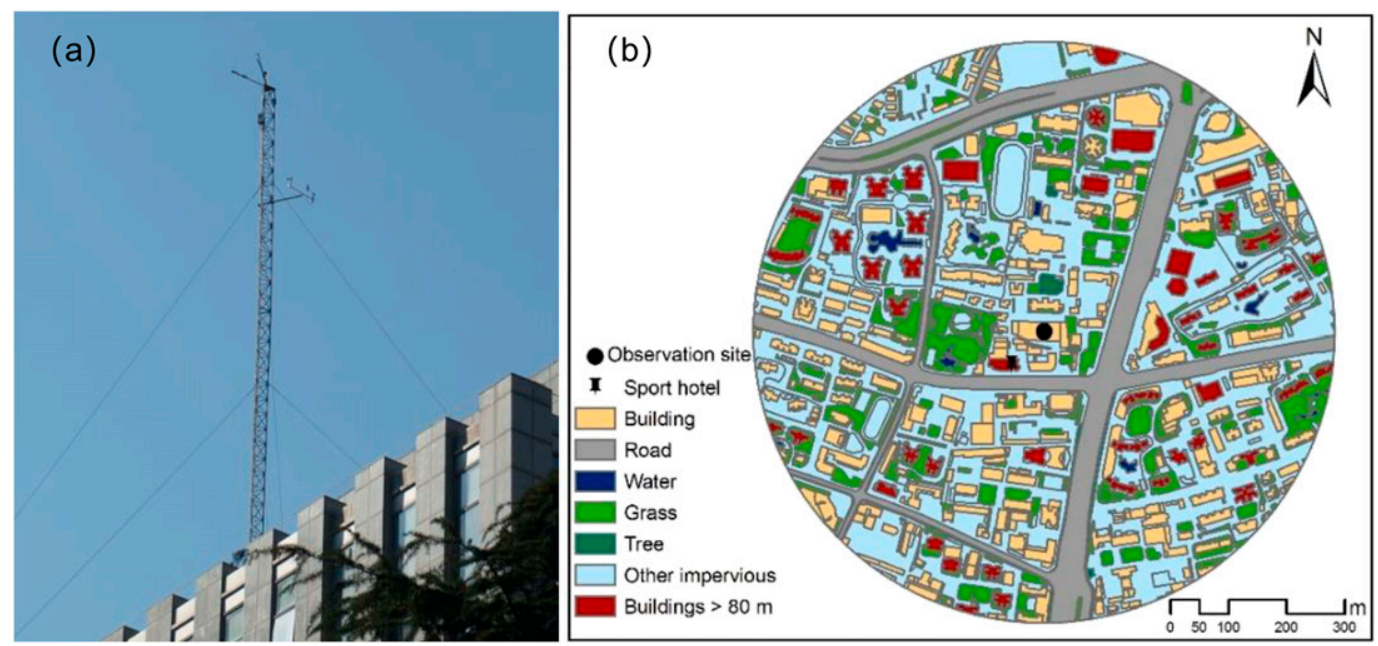

FIG. 1. Study site (XJH) in Shanghai: (a) flux tower and (b) land cover within $500 \mathrm{~m}$ (see Fig. 1 in Ao et al. 2016a).

$\rho_{\text {pop }}$ and heating and cooling degree days (HDD and CDD; Fig. 2a):

$$
Q_{F, S \text {,daily }}=\rho_{\text {pop }}\left(a_{F 0}+a_{F 1} \mathrm{CDD}+a_{F 2} \mathrm{HDD}\right),
$$

with daily HDD and CDD defined based on the hourly air temperature $T_{i}$ and a balance point temperature $T_{b}$ for human comfort, as

$$
\begin{aligned}
& \mathrm{HDD}=\sum_{i=1}^{24}\left(T_{b}-T_{i}\right) l, \\
& \mathrm{CDD}=\sum_{i=1}^{24}\left(T_{i}-T_{b}\right) l .
\end{aligned}
$$

Logic variable $l$ equals 1 when $\left(T_{b}-T_{i}\right)>0{ }^{\circ} \mathrm{C}$ and equals 0 when $\left(T_{b}-T_{i}\right)<0^{\circ} \mathrm{C}$ for $\mathrm{HDD}$, and vice versa for CDD, and $a_{F 0}$ is the base $Q_{F, S \text {,daily }}$ from all sources at the balance point temperature. The slopes $a_{F 1}$ and $a_{F 2}$ differ (Fig. 2a). Three coefficients $\left(a_{F 0}, a_{F 1}, a_{F 2}\right)$ need to be specified for a study site. Here daily results $\left(Q_{F, L \text {,daily }}\right)$ from LQF (see appendix A) are used to obtain these three coefficients. The fitted cooling slope $\left(a_{F 1}\right)$ is $0.0181 \mathrm{~W} \mathrm{~m}^{-2} \mathrm{~K}^{-1}$ (capita ha $\left.{ }^{-1}\right)^{-1}$, the heating slope $\left(a_{F 2}\right)$ is $0.0035 \mathrm{~W} \mathrm{~m}^{-2} \mathrm{~K}^{-1}$ (capita ha $\left.{ }^{-1}\right)^{-1}$, and $a_{F 0}=$ $0.3963 \mathrm{~W} \mathrm{~m}^{-2}$ (capita ha $\left.^{-1}\right)^{-1}$ with the single $T_{b}$ of $20^{\circ} \mathrm{C}$.

The diurnal profiles of the building $Q_{F B}$ for weekday, weekend, and holidays (Fig. 3a) are mainly based on diurnal variations of the city-scale electricity consumption data and further scaled by the electricity fraction of Shanghai (14\%; Table 1), industry fraction of the XJH site $(10 \%)$, and diurnal variation of population density (Yu and Wen 2016; W. Zhong et al. 2017). The diurnal profiles of the vehicle based $Q_{F B}$ (Fig. 3b) are derived from hourly highway traffic data for the inner ring of Shanghai in 2011 (see section 3a and appendix A; Su et al. 2014).
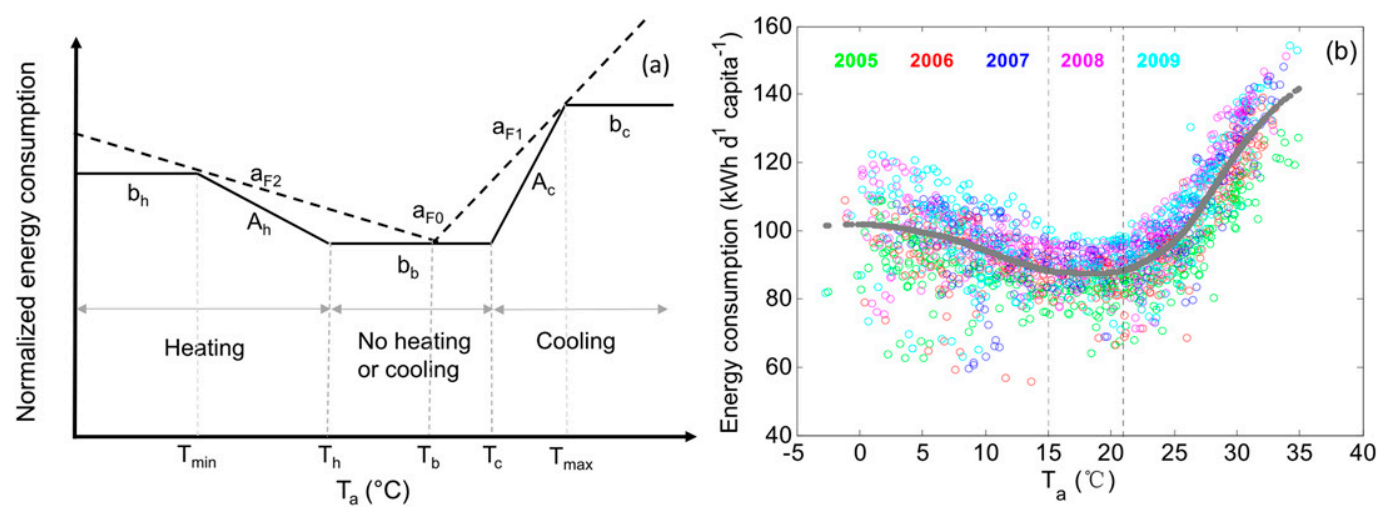

FIG. 2. Energy consumption response to air temperature: (a) two general response functions (see text for definitions) and (b) data for Shanghai (whole city daily electricity consumption; $\mathrm{kWh} \mathrm{day}^{-1}$ per capita; Shanghai Electric Power Company, http://www.sh.sgcc.com.cn/; Liu and Cao 2013) normalized by population (Shanghai Municipal Statistics Bureau 2016) and XJH daily mean air temperature $T_{a}$ for 2005-09 with general trend (gray, loess curve). 

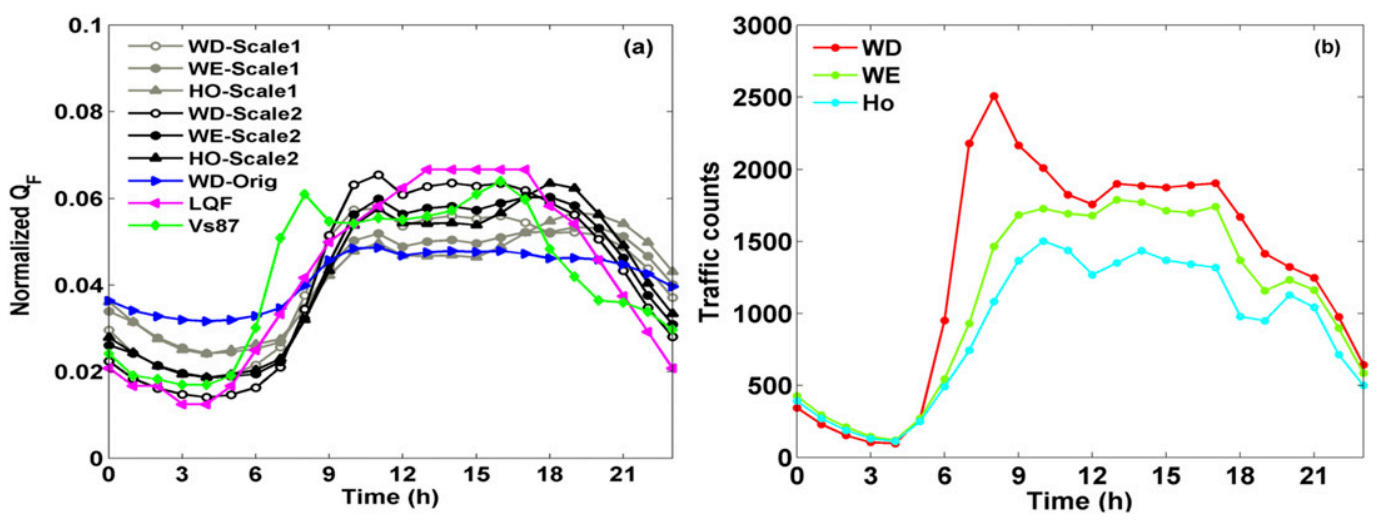

FIG. 3. Diurnal profiles for weekdays (WD), weekends (WE), and holidays (HO) of (a) building anthropogenic heat flux at the $\mathrm{XJH}$ site with $10 \%$ urban industry fraction used (scale 1), with variation of population density accounted for (scale 2), plus weekdays China LQF (Allen et al. 2011) and Vs87 (Grimmond 1992, Järvi et al. 2011) profiles and (b) traffic counts for highways near XJH in 2011 (Su et al. 2014; Shanghai Road Administration Bureau, http://www.highway.sh.cn).

\section{c. Estimation of irrigation}

Irrigation and street cleaning provides additional water to precipitation for runoff, evaporation, and soil moisture storage. In areas dominated by impervious surfaces, with limited available water for evaporation, the impact can be significant (Best and Grimmond 2016b; Sun et al. 2014). In SUEWS, the probable daily external water use $I_{e}$ is calculated as a function of the daily mean air temperature $T_{d}$ and number of days after rain $D_{\text {ar }}$ (Järvi et al. 2011):

$$
\begin{aligned}
I_{e}= & \sum_{i v=1}^{3} f_{i v}\left[f_{\text {aut }}\left(b_{0, a}+b_{1, a} T_{d}+b_{2, a} D_{\text {ar }}\right)+\left(1-f_{\text {aut }}\right)\right. \\
& \left.\times\left(b_{0, m}+b_{1, m} T_{d}+b_{2, m} D_{\text {ar }}\right)\right] .
\end{aligned}
$$

For each of the $i v$ vegetation types the irrigation fraction $\left(f_{i v}\right)$ and its method (automatic $f_{\text {aut }}$ or manual) are needed. The site specific coefficients $\left(b_{0, a}, b_{1, a}, b_{2, a}\right.$ and $\left.b_{0, m}, b_{1, m}, b_{2, m}\right)$ characterize the behavior of automated $a$ and manual $m$ irrigation during the period of external water use $\left(I_{e, \text { start }}\right.$ and $I_{e, \text { end }}$, days of year). The parameters used are given in Table 1. Additionally, the days of week when irrigation is permitted need to be specified (Shanghai: no restricted days of week). With the user-provided diurnal profiles of water use [see section 3d(1)], the daily irrigation is downscaled to hourly and then $5 \mathrm{~min}$.

\section{d. SUEWS model setup and parameters}

Version v2017a of SUEWS (Ward et al. 2016, 2017; Ward and Grimmond 2017) is used with a 5-min time

TABLE 1. Study site (XJH) parameter values used in SUEWS. See text for definitions and sources not given here (Järvi et al. 2011). OHM coefficient $\left(a_{1}, a_{2}, a_{3}\right)$ are averages of values from different sources: paved (Doll et al. 1985; Asaeda and Ca 1993; Narita et al. 1984; Anandakumar 1999); buildings (Meyn 2001), vegetation (Fuchs and Hadas 1972; Novak 1981; McCaughey 1985; Asaeda and Ca 1993; Doll et al. 1985), bare soil (Fuchs and Hadas 1972; Novak 1981; Asaeda and Ca 1993), and water (South et al. 1998). EveTr is evergreen trees and DecTr is deciduous trees. Measurement height is $z_{m}$.

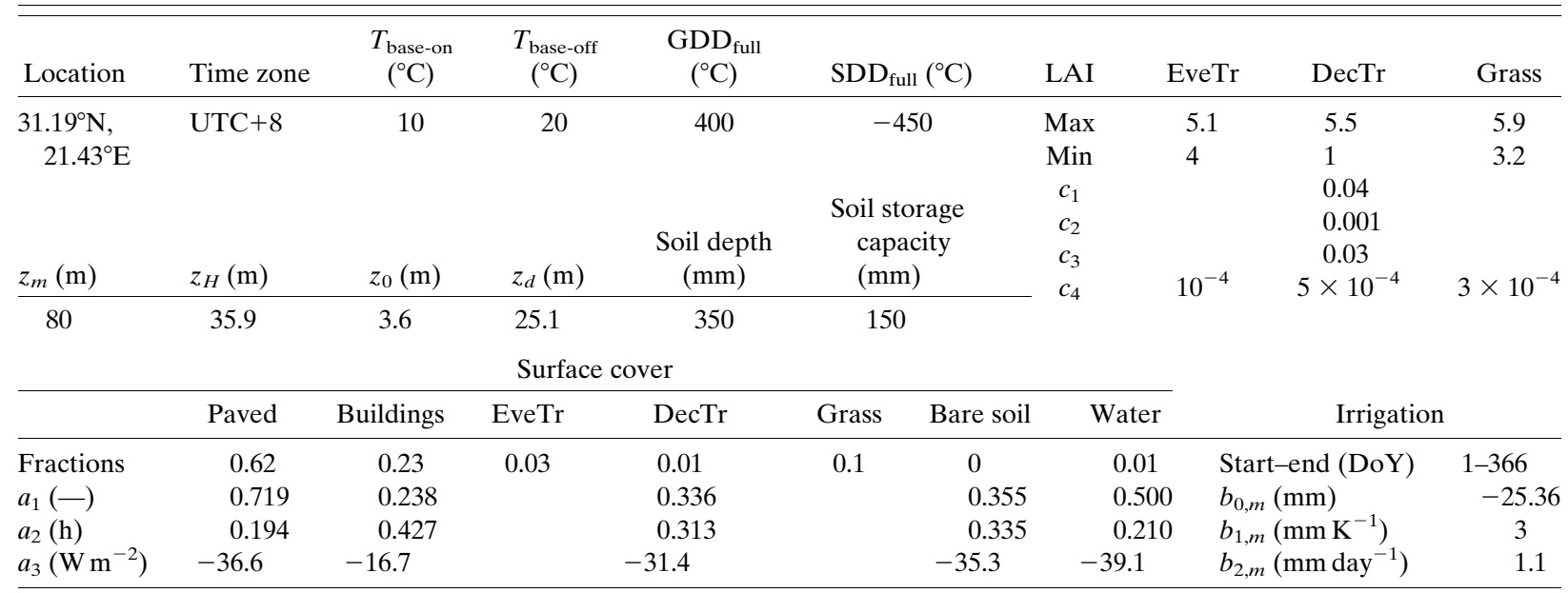


step but forced by 60 -min meteorological input data. The incoming shortwave radiation flux $K \downarrow$, air temperature $T_{a}$, pressure $p$, relative humidity $(\mathrm{RH})$, and precipitation $P$ are linearly interpolated to $5 \mathrm{~min}$ by SUEWS. The 60-min averaged (by SUEWS) outputs are used in the comparison with observations. The parameter values used to characterize the study site $(\mathrm{XJH})$ are given in Table 1.

Surface cover and mean building height $z_{H}$ parameters are derived from GIS and ground survey data (Ao et al. 2016a). The roughness length $z_{0}$ and the zero-plane displacement height $z_{d}$ method selected are the simple fixed fraction of the mean building height $z_{H}$ or rule of thumb $\left(0.1 z_{H}\right.$ and $0.7 z_{H}$; Grimmond and Oke 1999). Given the conclusions of Kent et al. (2017) and Tang et al. (2016), runs are also undertaken using the Kanda et al. (2013) method. Mean values calculated around the site ( $1^{\circ}$ interval) gave $z_{0}=7.6$ and $z_{d}=55 \mathrm{~m}$. The model result difference from that of rule-of-thumb method is small (not shown).

The leaf area index (LAI) or phenology has a critical influence on the latent heat flux $Q_{E}$ and timing of appropriate seasons. It dynamically responds to growing degree days (GDD) and senescence degree days (SDD). Phenology parameters are determined from observations and photographs with local daily mean air temperatures [leaf-on $\left(T_{\text {base-on }}\right)$, leafoff $\left.\left(T_{\text {base-off }}\right)\right]$, growing degree days until full LAI $\left(G D_{\text {full }}\right)$, and senescence degree days that initiate leaf-off $\left(\mathrm{SDD}_{\text {full }}\right)$ are calculated as cumulative values of GDD and SDD during growing and senescence periods in Shanghai (around 15 March20 May and 15 October-20 December, respectively). The equation used for GDD (SDD) in SUEWS is (McMaster and Wilhelm 1997):

$$
\begin{aligned}
\mathrm{GDD} & =\left[\left(T_{\max }+T_{\min }\right) / 2\right]-T_{\text {base-on }}, \\
\mathrm{SDD} & =\left[\left(T_{\max }+T_{\min }\right) / 2\right]-T_{\text {base-off }},
\end{aligned}
$$

where $T_{\max }$ and $T_{\min }$ are daily maximum and minimum air temperature, respectively. GDD (SDD) must be greater (smaller) than 0 , and if not, they are forced to 0 . As expected, the Shanghai $T_{\text {base-on }}$ and $T_{\text {base-off }}\left(10^{\circ}\right.$ and $20^{\circ} \mathrm{C}$; Table 1) are much warmer than for Helsinki and Montreal $\left(5^{\circ}\right.$ and $10^{\circ} \mathrm{C}$; Järvi et al. 2014) and London $\left(6^{\circ}\right.$ and $11^{\circ} \mathrm{C}$; Ward et al. 2016). Latitude strongly impacts the length of growing (senescence) season. The daily LAI for each vegetation type $i v$ is a function of the previous day LAI $\left(\mathrm{LAI}_{d-1, i v}\right)$, daily mean air temperature $T_{d}$, and day length $t_{d}$ (Järvi et al. 2014). For leaf-on, $T_{d}>T_{\text {base-on }}$ :

$$
\mathrm{LAI}_{d, i v}=\mathrm{LAI}_{d-1, i v}^{c_{1}} \mathrm{GDD}_{2}+\mathrm{LAI}_{d-1, i v} .
$$

For leaf-off, it may be initiated by a thermal condition only $\left(T_{d}<T_{\text {base-off }}\right)$ :

$$
\mathrm{LAI}_{d, i v}=\mathrm{LAI}_{d-1, i}^{c_{3}} \mathrm{SDD}_{4}+\mathrm{LAI}_{d-1, i v},
$$

or also account for day length $\left(t_{d}<12 \mathrm{~h}\right)$

$$
\mathrm{LAI}_{d, i v}=\mathrm{LAI}_{d-1, i v} c_{3} \mathrm{SDD} c_{4}+\mathrm{LAI}_{d-1, i v} .
$$

From sensitivity experiments (not shown), it is found that accounting for day length [Eq. (5c)] is unsuitable at this subtropical site (small variation of $t_{d}$ ) as simulated leaf-off occurs too early and the senescence is too fast. Hence, Eq. (5b) is adopted in this study. The parameters $c_{1,2,3,4}$ control the changing rate of LAI. Parameter $c_{1,2,3}$ values are the same in Järvi et al. (2014) for Helsinki, while for $c_{4}$ for evergreen trees, a smaller value is used based on local visual/photograph surveys that leaves are still partially active to late December. The subtropical climate and careful maintenance (e.g., turf replacement if it turns yellow) at the Shanghai site results in a longer growing season for grass than higher latitudes. Based on photographs taken around the XJH site in winter and spring (not shown), the grass remains green in winter months. Therefore, the minimum LAI for grass is increased from 1.6 in Järvi et al. (2014) to 3.2 at our site (Table 1), which results in a better model performance, especially in winter and spring seasons (not shown).

Previous evaluation of the radiation components of SUEWS (Ao et al. 2016b) found good performance. The net all-wave radiation flux $Q^{*}$ modeled with downward longwave radiation flux $L_{\downarrow}$ estimated as a function of RH and $T_{a}$. The storage heat flux is calculated using the objective hysteresis model (OHM; Grimmond et al. 1991), with $Q^{*}+Q_{F}$ (rather than only $Q^{*}$ ) used:

$\Delta Q_{S}=\sum_{i} f_{i}\left[a_{1 i}\left(Q^{*}+Q_{F}\right)+a_{2 i} \frac{\partial\left(Q^{*}+Q_{F}\right)}{\partial t}+a_{3 i}\right]$,

where $f_{i}$ is the fraction for the $i$ th surface type, and $t$ is the time. The three coefficients $\left(a_{1}, a_{2}, a_{3}\right)$ of OHM are from the literature (Table 1).

The latent heat flux $Q_{E}$ is modeled using the modified Penman-Monteith equation (Grimmond and Oke 1991). More detailed description of the parameterization of $Q_{E}$ is given in section 3c. The sensible heat flux $Q_{H}$ is calculated as a residual of the surface energy balance. The soil layer underneath each surface type (except water surface) is assumed to be $350 \mathrm{~mm}$, with a maximum water capacity of $150 \mathrm{~mm}$. To obtain appropriate initial conditions, SUEWS is run for one year with the 2012/13 forcing to get probable initial state of soil moisture storage and leaf area index. 


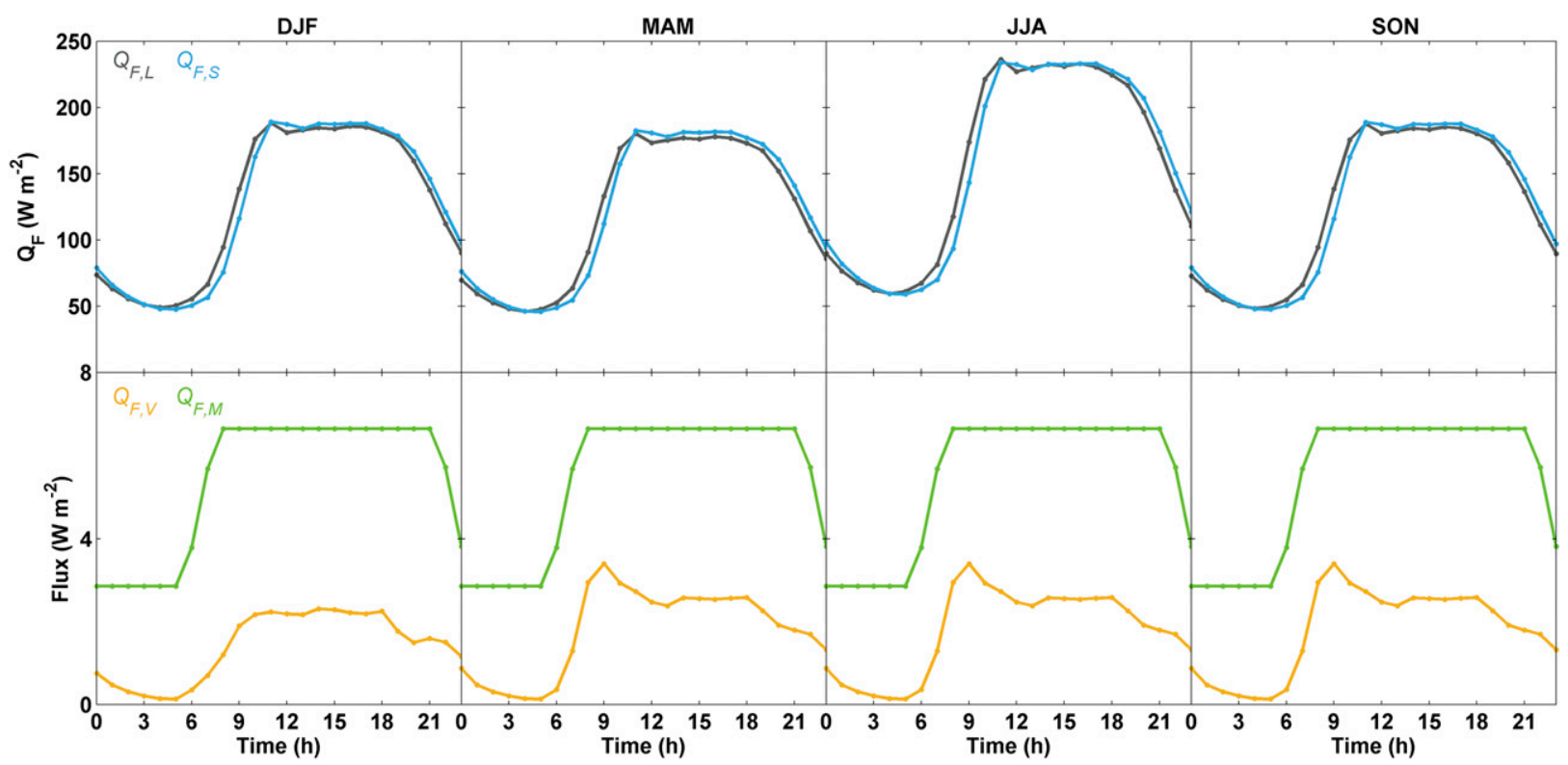

FIG. 4. Seasonal mean diurnal variations of $Q_{F}$ at XJH estimated by LQF and SUEWS (section 2b), LQF metabolic heat $Q_{F, M}$, and vehicle heat $Q_{F, V}$ emissions.

\section{Results}

\section{a. Anthropogenic heat fluxes}

The diurnal profiles of the building anthropogenic heat flux for weekdays, weekends, and holidays are similar (Fig. 3a): all are low from 0000 to 0600 LST, then increase gradually until 1100 LST, with a small decrease at 1200 LST. Thereafter, the three diurnal patterns begin to diverge. During weekdays values remain relatively constant from 1200 to 1700 LST, then decrease steadily. During weekends the timing of this decrease lags by $2 \mathrm{~h}$ (i.e., from 1900 LST), whereas on holidays there is a stronger evening peak around 1900 LST.

The diurnal profiles that account for population variations (Fig. 3a) have much larger amplitudes than the original profiles and are similar in amplitude to the default LQF and SUEWS Vancouver 1987 (Vs87) profiles (Grimmond 1992; Järvi et al. 2011) and to other studies, for example, in Japan (Takane et al. 2017). The ratios of the maximum and minimum value for scaled weekday, weekend, and holiday are 4.7,3.2, and 3.4, respectively. The corresponding values for LQF and SUEWS $Q_{F}$ schemes are 5.3 and 3.8, respectively.

Seasonal differences in diurnal patterns and magnitudes of the vehicle heat emissions are relatively small (not shown). The weekday morning peak (at 0800 LST) is distinct whereas the evening peak (at 1700 LST; Fig. 3b) is unlike North American cities, where the evening peak is generally stronger than the morning peak (Grimmond 1992; Hallenbeck et al. 1997; Chow et al. 2014). This may be because the end of work varies between companies; while most institutions or government offices finish between 1700 and 1800 LST, many people often stay at the office in the evening. Additionally, shopping malls and restaurants are open until 2100-2200 LST. The weekend pattern, without distinct peaks, slowly increases in the morning then stays flat from about 1000 to 1700 LST. Holidays have a similar pattern to the weekend but with smaller magnitudes.

The LQF and SUEWS $Q_{F}$ results are very similar (Fig. 4). As the three SUEWS coefficients $\left(a_{F 0}, a_{F 1}, a_{F 2}\right)$ are derived using the LQF results, this is expected. The larger summertime results are a function of the larger $a_{F 2}$ slope and therefore dependence on CDD, as expected. The peak mean daily summer $Q_{F, L}$ (Fig. 4) is around $236 \mathrm{~W} \mathrm{~m}^{-2}$; winter and autumn mean fluxes peak are similar $\left(190 \mathrm{~W} \mathrm{~m}^{-2}\right)$ and spring is slightly smaller $\left(180 \mathrm{~W} \mathrm{~m}^{-2}\right)$. These values, using the new response function, give a slightly bigger seasonal variation than the original function (not shown). The building heat emission is the major subcomponent, accounting for about $95 \%$ of the total $Q_{F, L}$. The modeled metabolic heat emission $Q_{F M}$ is about $3 \mathrm{~W} \mathrm{~m}^{-2}$ at night and $7 \mathrm{~W} \mathrm{~m}^{-2}$ during daytime and does not show seasonal variations. Seasonal differences in vehicle heat emissions also are very small, with $Q_{F V}$ around $3 \mathrm{~W} \mathrm{~m}^{-2}$ in the daytime. The small (or no) seasonal variation for $Q_{F V}$ and $Q_{F M}$ is because the same parameter settings are assumed for each season, as there is a lack of information to suggest otherwise. The difference between 

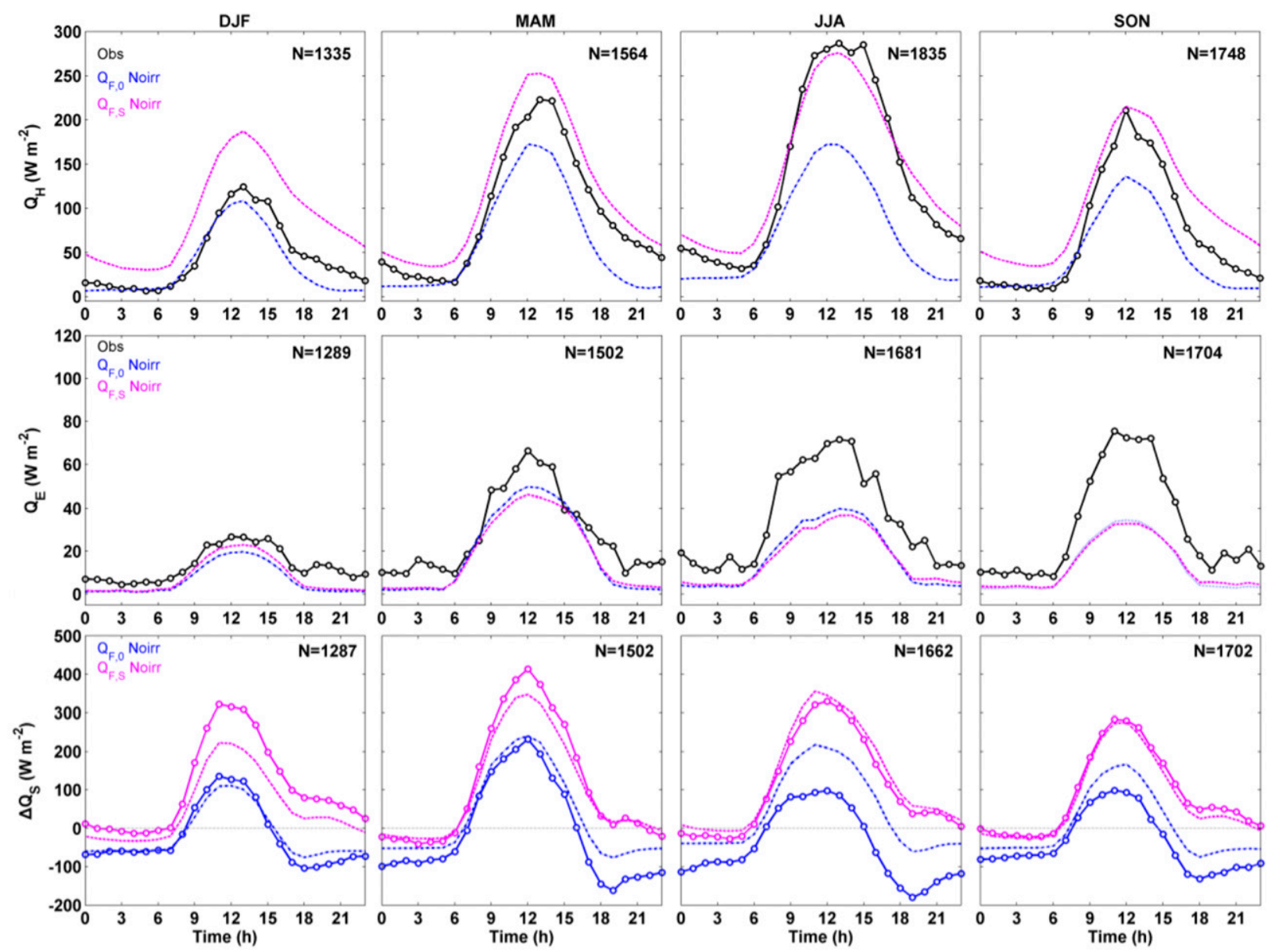

FIG. 5. Seasonal mean diurnal cycles of observed and simulated sensible heat flux $Q_{H}$, latent heat flux $Q_{E}$, and storage heat flux $\Delta Q_{S}$ for the two experiments $\left(Q_{F, 0}\right.$ Noirr, $Q_{F, S}$ Noirr). See Table 2 for statistical performance metrics and Figs. C1-C3 in appendix C for scatterplots.

winter and the other three seasons is because more holidays occur in winter. The magnitudes of $Q_{F M}$ and $Q_{F V}$ estimated here are similar to previous studies (Chow et al. 2014; Lu et al. 2016; Stewart and Kennedy 2017). There is a high correlation coefficient $(0.97)$ between hourly $Q_{F, S}$ and $Q_{F, L}$. Given the simplicity of SUEWS $Q_{F}$, the dynamic temperature response, and comparable results to LQF, the SUEWS $Q_{F}$ is regarded as an appropriate method to use after careful determination of the parameters. As the purpose of this study is the evaluation of SUEWS, the SUEWS $Q_{F}$ are used in the following sections.

\section{b. Impact of $Q_{F}$ on surface energy fluxes}

Two simulations to examine the impact of $Q_{F}$ on the surface energy balance fluxes in Shanghai are conducted (Figs. 5, C1-C3): 1) assuming $Q_{F}=0 \mathrm{~W} \mathrm{~m}^{-2}$ (hereafter $Q_{F, 0}$ Noirr) and 2) using SUEWS determined flux $\left(Q_{F, S}\right.$ Noirr). No irrigation is considered in these two simulations (Noirr).
When $Q_{F, 0}$ is assumed, the turbulent sensible heat flux $Q_{H}$ is generally underestimated [negative mean bias error (MBE)] for the four seasons, especially during afternoon and midnight. Including $Q_{F}$ leads to a large increase in $Q_{H}$. The seasonal mean diurnal $Q_{H}$ is overestimated through the entire day in winter, spring, and autumn, while in summer daytime $Q_{H}$ is slightly underestimated and nocturnal $Q_{H}$ is overestimated (Fig. 5). The MBE for the four seasons are all positive when $Q_{F, S}$ is used (Table 2). The overall performance for $Q_{H}$ is improved in spring, summer, and autumn with rootmean-square error (RMSE) decreased $(-7,-33$, and $-12 \mathrm{~W} \mathrm{~m}^{-2}$, respectively). The coefficient of determination $R^{2}$ increases slightly in spring and summer for the $Q_{F, S}$ case. But the RMSE and MBE increase in winter, suggesting winter $Q_{F}$ may be overestimated.

Given the complex sampling issues, direct measurements of the storage heat flux $\Delta Q_{S}$ in an urban area with a wide range of tall $3 \mathrm{D}$ volumes has not been undertaken. Instead, the "observed" $\Delta Q_{S}$ is estimated as 
TABLE 2. SUEWS model performance statistics (cf. observations) by season for sensible heat flux $Q_{H}$, latent heat flux $Q_{E}$, and storage heat flux $\Delta Q_{S}$ for four experiments (Exp): Exp 1 is a base scenario without $Q_{F}$ and irrigation, $\operatorname{Exp} 2$ is $Q_{F}$ modeled without irrigation, and Exp 3 and Exp 4 are irrigation scenarios. Figures $\mathrm{C} 1-\mathrm{C} 3$ provide the number $N$ of 60 -min data points analyzed. Statistics and notation are given in appendix $\mathrm{B}$.

\begin{tabular}{|c|c|c|c|c|c|c|c|c|c|c|c|c|c|c|c|c|}
\hline \multirow[b]{2}{*}{ Exp } & \multirow[b]{2}{*}{ Season } & \multicolumn{5}{|c|}{$Q_{H}$} & \multicolumn{5}{|c|}{$Q_{E}$} & \multicolumn{5}{|c|}{$\Delta Q_{S}$} \\
\hline & & $\bar{O}$ & $R^{2}$ & RMSE & MBE & MAE & $\bar{O}$ & $R^{2}$ & RMSE & MBE & MAE & $\bar{O}$ & $R^{2}$ & RMSE & MBE & MAE \\
\hline \multirow[t]{4}{*}{ 1) $Q_{F, 0}$ Noirr } & DJF & 48.9 & 0.57 & 42.6 & -10.7 & 29.7 & 14.1 & 0.20 & 17.5 & -6.9 & 12.1 & -17.8 & 0.77 & 50.6 & 4.4 & 37.0 \\
\hline & MAM & 92.7 & 0.56 & 73.3 & -32.4 & 50.7 & 27.5 & 0.23 & 34.7 & -8.9 & 23.0 & -14.3 & 0.74 & 91.4 & 42 & 66.6 \\
\hline & JJA & 136.7 & 0.62 & 111.6 & -64.0 & 72.6 & 34.2 & 0.10 & 51.8 & -17.6 & 34.3 & -47.6 & 0.5 & 131.4 & 87.8 & 97.4 \\
\hline & SON & 75.3 & 0.64 & 70.8 & -25.5 & 41.6 & 32.4 & 0.27 & 44.1 & -18.9 & 27.5 & -37 & 0.45 & 94.1 & 44.1 & 61.0 \\
\hline \multirow[t]{4}{*}{ 2) $Q_{F, S}$ Noirr } & DJF & & 0.57 & 63.2 & 46.4 & 52.6 & & 0.18 & 17.2 & -5.3 & 11.9 & 114.3 & 0.86 & 77.0 & -54.5 & 62.0 \\
\hline & MAM & & 0.60 & 66.7 & 22.9 & 51.0 & & 0.20 & 35.5 & -9.6 & 23.0 & 105.8 & 0.81 & 82.8 & -12.4 & 60.2 \\
\hline & JJA & & 0.68 & 79.1 & 6.3 & 53.4 & & 0.08 & 52.5 & -18.1 & 34.8 & 106.9 & 0.69 & 92.4 & 19.2 & 63.4 \\
\hline & SON & & 0.64 & 68.4 & 31.8 & 54.0 & & 0.22 & 44.7 & -18.6 & 27.8 & 91.2 & 0.63 & 79.9 & -13.0 & 56.0 \\
\hline \multirow[t]{4}{*}{ 3) $Q_{F, S} \operatorname{Irr}$} & DJF & & 0.58 & 61.6 & 44.9 & 51.4 & & 0.19 & 16.9 & -3.7 & 11.8 & & & & & \\
\hline & MAM & & 0.56 & 65.9 & 9.5 & 48.9 & & 0.23 & 36.3 & 3.8 & 24.5 & & & & & \\
\hline & JJA & & 0.62 & 101.8 & -32.2 & 62.2 & & 0.15 & 57.0 & 18.9 & 39.7 & & & & & \\
\hline & SON & & 0.60 & 68.9 & 9.5 & 48.2 & & 0.36 & 37.0 & 3.4 & 24.7 & & & & & \\
\hline \multirow[t]{4}{*}{ 4) $Q_{F, S} \operatorname{Irr} 3 \mathrm{dGap}$} & DJF & & 0.57 & 62.1 & 45.3 & 51.7 & & 0.19 & 16.9 & -4.0 & 11.8 & & & & & \\
\hline & MAM & & 0.58 & 65.6 & 14.4 & 49.3 & & 0.23 & 34.9 & -1.6 & 23.5 & & & & & \\
\hline & JJA & & 0.64 & 89.7 & -15.3 & 56.5 & & 0.16 & 49.3 & 3.3 & 34.0 & & & & & \\
\hline & SON & & 0.63 & 67.4 & 18.3 & 49.7 & & 0.34 & 37.7 & -5.1 & 24.3 & & & & & \\
\hline
\end{tabular}

the residual of the surface energy balance $\left(\Delta Q_{S}=Q^{*}+\right.$ $Q_{F}-Q_{H}-Q_{E}$ ), therefore including considerable uncertainties. As a result, the observed $\Delta Q_{S}$ differs with $Q_{F}$ used. If $Q_{F}$ is assumed to be $0 \mathrm{~W} \mathrm{~m}^{-2}$, SUEWS generally performs well in winter, spring, and autumn with RMSEs of 51,91, and $94 \mathrm{~W} \mathrm{~m}^{-2}$, respectively (Fig. 5, Table 2). The $R^{2}$ is above 0.7 both in winter and spring but considerably lower (0.45) in autumn. Although the shape of the diurnal pattern including sign transition is well replicated, the nocturnal $\Delta Q_{S}$ is slightly underestimated. In summer, $\Delta Q_{S}$ is substantially overestimated during the daytime and underestimated at night (absolute values). When $Q_{F}$ is included, a large portion goes into the storage heat flux. There is a large improvement in summertime RMSE $\left(39 \mathrm{~W} \mathrm{~m}^{-2}\right.$ decrease; Table 2$)$ and smaller in spring and autumn (9 and $14 \mathrm{~W} \mathrm{~m}^{-2}$ decreases, respectively). However, wintertime RMSE deteriorates $\left(+26 \mathrm{~W} \mathrm{~m}^{-2}\right)$. The coefficients of determination have substantial increases for all seasons $(0.09,0.07,0.19$, and 0.18 increases, respectively). From the above analysis, it appears the simulated wintertime $Q_{F}$ may have greater uncertainty than other seasons.

\section{c. Latent heat flux}

The underestimation of $Q_{E}$, especially in summer and autumn, is explored by considering the surface resistance $r_{s}$ (or its reciprocal, surface conductance $g_{s}$ ) as evapotranspiration is very sensitive to it. The overall capability of water to be transported through the surface (soil, leaves, etc.) to the lower atmosphere is captured by $g_{s}$. The Jarvis-Stewart model (Jarvis 1976; Stewart
1988), which has been used extensively in previous studies (e.g., Grimmond and Oke 1991; Ogink-Hendriks 1995; Matsumoto et al. 2008; Järvi et al. 2011; Ward et al. 2016), is employed in SUEWS to estimate $g_{s}$. The response of stomata opening and closing, and other surface controls are included as a synergistic function of the LAI, incoming solar radiation $K \downarrow$, specific humidity deficit $\Delta q$, air temperature $T_{a}$, and soil moisture deficit $\Delta \theta$ :

$$
g_{s}=G_{1} g(\mathrm{LAI}) g(K \downarrow) g(\Delta q) g\left(T_{a}\right) g(\Delta \theta) .
$$

Although the specific mathematical formulations of each subfunction may differ among studies, the general form is similar. The five subfunctions are presumed to be independent from each other. Although $\Delta q$ and $T_{a}$ are usually highly correlated, some studies found that incorporating both functions provides better results [e.g., Khatun et al. (2011) for East Asian forests]. Moreover, the shapes of the $g_{s}$ dependence curves to $\Delta q$ and $T_{a}$ are very different (Ward et al. 2016). Low $T_{a}$ often coincides with low $\Delta q$, while low $T_{a}$ constrains $g_{s}$ but low $\Delta q$ favors $g_{s}$. The subfunctions range from 0 to 1 , to reduce the maximum surface conductance, except for $g$ (LAI):

$$
g(\mathrm{LAI})=\sum_{i v}\left(f_{i v} g_{\max , i v} \frac{\mathrm{LAI}_{i v}}{\mathrm{LAI}_{\max , i v}}\right),
$$

where for the three vegetation types (evergreen, deciduous, grass) $i v$ the fraction of area $f_{i v}$, maximum conductance $g_{\text {max }, i v}$, and the maximum LAI $\left(\mathrm{LAI}_{\max , i v}\right)$ are 


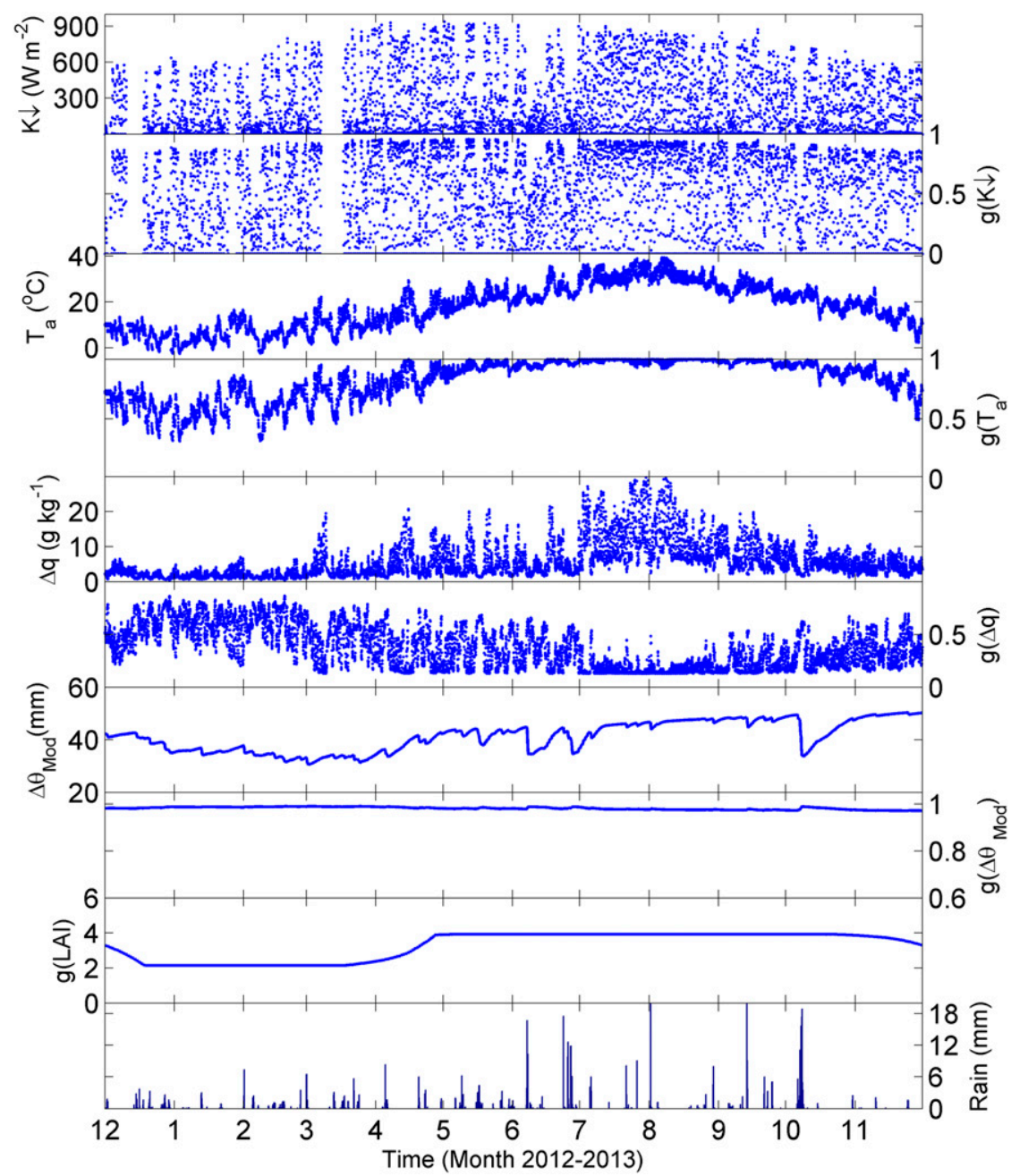

FIG. 6. Hourly time series of surface conductance related environmental variables and corresponding subcomponents [Eqs. (8)-(12)]. Irrigation is not considered here.

needed. It should be noted $g_{\max , i v}$ is usually larger for irrigated than unirrigated vegetation. For radiative control, the observed maximum incoming solar radiation $K_{\downarrow \text { max }}$ is used (here, set to $1200 \mathrm{~W} \mathrm{~m}^{-2}$ )

$$
\left.g(K \downarrow)=\frac{K \downarrow /\left(G_{2}+K \downarrow\right)}{K \downarrow_{\max } /\left(G_{2}+K \downarrow\right. \text { max }}\right),
$$

where $G_{2}$ and other coefficients $\left(G_{1}-G_{6}\right)$ are obtained from observations (Grimmond and Oke 1991; Ward et al. 2016). For humidity,

$$
g(\Delta q)=G_{3}+\left(1-G_{3}\right) G_{4}^{\Delta q} .
$$

For air temperature, lower $T_{L}$ and upper $T_{H}$ temperature limits are used when evaporation turns off $\left[g\left(T_{a}\right)=0\right]$. Here $T_{L}$ and $T_{H}$ are set to a relatively wide range as $-10^{\circ}$ and $55^{\circ} \mathrm{C}$, respectively:

$$
g\left(T_{a}\right)=\frac{\left(T_{a}-T_{L}\right)\left(T_{H}-T_{a}\right)^{T_{c}}}{\left(G_{5}-T_{L}\right)\left(T_{H}-G_{5}\right)^{T_{c}}},
$$

with $T_{c}=\left(T_{H}-G_{5}\right) /\left(G_{5}-T_{L}\right)$.

The normalized form of $g(\Delta \theta)$ enables $g(\Delta \theta)=1$ when there is no soil moisture deficit and $g(\Delta \theta)=0$ when the soil moisture deficit equals to the wilting point $\left(\Delta \theta_{\mathrm{wp}}\right.$, here set to $120 \mathrm{~mm}$ ):

$$
g(\Delta \theta)=\frac{1-\exp \left[G_{6}\left(\Delta \theta-\Delta \theta_{\mathrm{wp}}\right)\right]}{1-\exp \left(-G_{6} \Delta \theta_{\mathrm{wp}}\right)} .
$$

The hourly time series for the whole year of each subcomponent of $g_{s}$ [Eqs. (8)-(12)] and for $g_{s}$ itself [Eq. (7)] without irrigation are shown in Figs. 6 and 7. In July and August, modeled $g_{s}$ is smaller $\left(<1 \mathrm{~mm} \mathrm{~s}^{-1}\right)$ than other months, explaining the underestimation of $Q_{E}$. As $g_{s}(K \downarrow)$, 


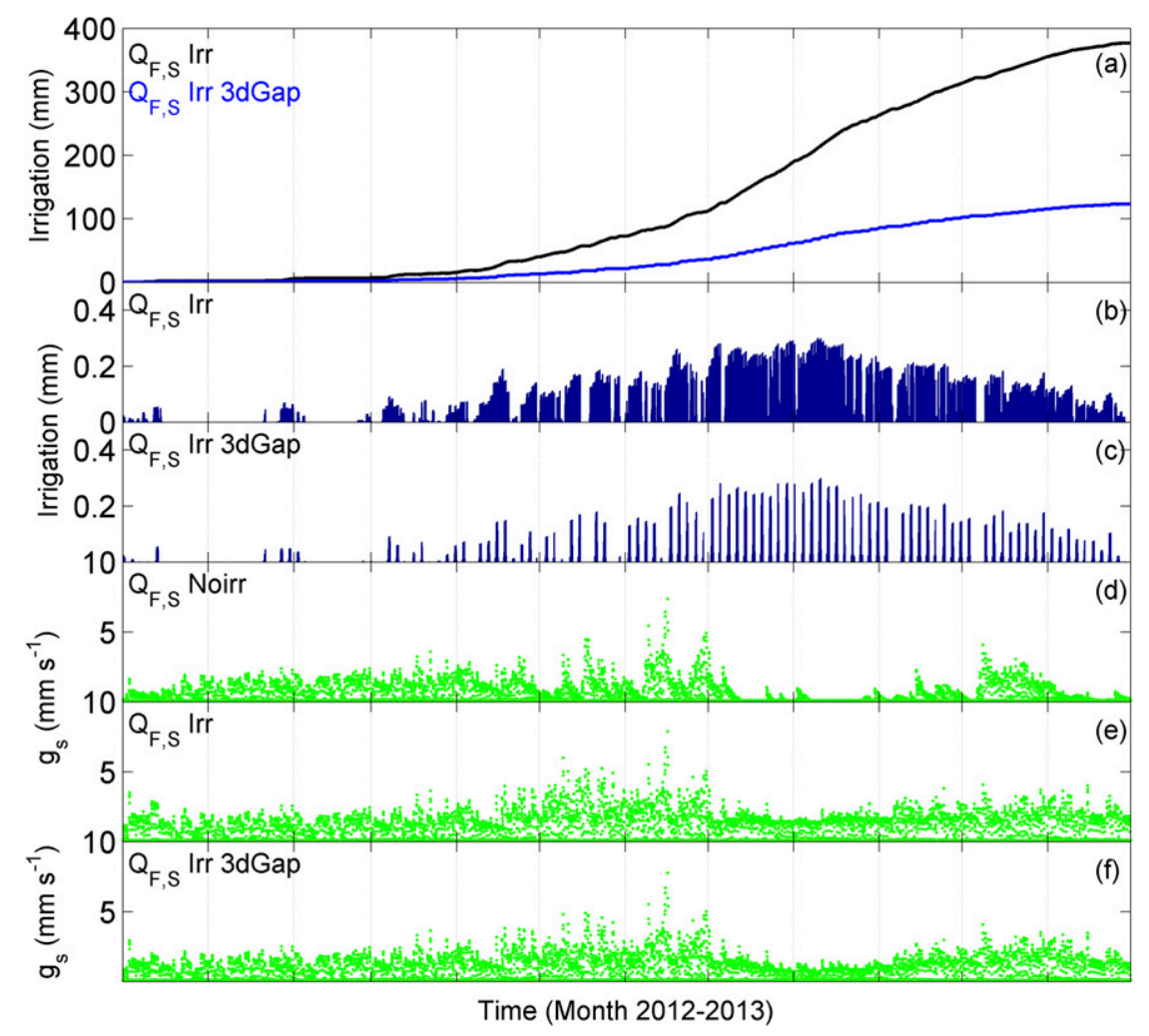

FIG. 7. Variation in irrigation (a) cumulative annual total for two scenarios, timing of irrigation for experiment (b) $Q_{F, S}$ Irr and (c) $Q_{F, S}$ Irr 3dGap, and hourly modeled surface conductance $g_{s}$ for three scenarios: (d) $Q_{F, S}$ Noirr, (e) $Q_{F, S}$ Irr, and (f) $Q_{F, S}$ Irr 3dGap.

$g_{s}\left(T_{a}\right)$, and $g_{s}(\Delta \theta)$ all have relatively high values from July to September, $K \downarrow, T_{a}$, and $\Delta \theta$ are not key factors for the underestimation of $Q_{E}$. July and August 2013 $g_{s}(\Delta q)$ values are quite small as there are very large specific humidity deficits, associated with the unusually hot and dry conditions (Ao et al. 2016a). Despite this the observed $Q_{E}$ in these months remained relatively large, probably maintained by irrigation (section $3 \mathrm{~d}$ ).

\section{d. Irrigation}

\section{1) IrRigation SCHEME EVALUATION}

In Shanghai, it is not easy to obtain accurate external water use data. The behaviors are characterized from field observations, including direct conversations with those undertaking irrigation, and a literature review. At the Shanghai Meteorological Service (150-m radius of site) irrigation is conducted throughout the year on any day of the week. It occurs most intensively in July and August when it is hot. Generally, only grass is irrigated. The mostly manual irrigation usually occurs twice on hot summer days (0600-1100 LST and 1500-1900 LST) in different areas, so by the end of the day the whole area is irrigated. In winter irrigation occurs once per day (morning or evening) every 3-4 days. Street cleaning and park irrigation are sometimes observed. Irrigation of private gardens may be extremely variable (Mitchell et al. 2001). Based on this, a diurnal profile is assumed. The modeled latent heat flux using this field-based diurnal profile when compared with an evenly distributed profile has very small differences (seasonal $\triangle$ RMSE differences $<0.5 \mathrm{~W} \mathrm{~m}^{-2}$, not shown). Variables $f_{\text {grass }}$ and $f_{\text {aut }}$ are set to 0.4 and 0 , respectively. For $b_{0, m}, b_{1, m}$, and $b_{2, m}$, the same values as Järvi et al. (2011) are used (Table 1), which are based on Vancouver (Grimmond and Oke 1986; Grimmond and Oke 1991). The water from these are assumed to be included in the coefficients used, as no additional detailed information is available.

Previous studies show that evaporation is very sensitive to both the amount and frequency of irrigation (Grimmond and Oke 1986; Vahmani and Hogue 2014). To test the influence of irrigation frequency on $Q_{E}$, the following scenarios are tested: 1) SUEWS irrigation [Eq. (3)] is used with parameter that set irrigation to 0 within $6 \mathrm{~h}$ of rain and with the other parameters as specified in Table 2 (hereafter $Q_{F, S}$ Irr), and 2) as in scenario 1 , but with irrigation every 3 days independent of weather conditions (Table 2; hereafter $Q_{F, S}$ Irr 3dGap). 
The monthly water use data from January 2013 to December 2013 for the entire Shanghai area (Chang et al. 2015) provided by the Shanghai Water Authority (http://www.shanghaiwater.gov.cn/) are used to evaluate the SUEWS irrigation scheme. As December 2012 water use data are unavailable, December 2013 data are used. The water use data are split between indoor and outdoor, assuming the minimum month value is the indoor water use (minimum month method; Vahmani and Hogue 2014). Differences from this minimum are considered to be outdoor water use, and indicative of irrigation and/or street cleaning, etc. Uncertainties arise from using city-level data given land use and land cover variations around this large city. Total city water use distributed to the Xuhui district (area of $54.76 \mathrm{~km}^{2}$ ) where the study site is located is based on the annual water use fraction. Further, it is assumed that irrigation is applied to all vegetation and half the road (street cleaning) areas. The annual water use fraction, vegetation, and road cover fractions for the Xuhui district are $0.017,0.232$, and 0.522 , respectively (Shanghai Municipal Statistics Bureau 2016). The modeled monthly cumulative results from the irrigation scenarios are evaluated against the estimated outdoor water use (Fig. 8). The peak outdoor water use months occurred in July and August (around $\left.18.5 \mathrm{~mm} \mathrm{month}^{-1}\right)$, with annual total $\left(97 \mathrm{~mm} \mathrm{yr}^{-1}\right)$ corresponding to $9 \%$ of the annual rainfall amount. The monthly trend for the Irr 3dGap scenario matches the outdoor water use estimates relatively well, with a bit larger annual irrigation amount $(140 \mathrm{~mm})$. However, the scenario with only a 6 -h gap after rain (Irr) results in much larger irrigation rates than suggested from the city outdoor water use (Fig. 8). Therefore, the Irr $3 \mathrm{dGap}$ scenario is considered more appropriate for the study area.

\section{2) IMPACT OF IRRIGATION ON SIMULATED SURFACE ENERGY FLUXES}

For the first irrigation scenario $\left(Q_{F, S}\right.$ Irr; Figs. 9, C1), the modeled $Q_{E}$ have small differences compared to $Q_{F, S}$ Noirr in winter $\left(\triangle \mathrm{RMSE}=-0.3 \mathrm{~W} \mathrm{~m}^{-2}, \Delta \mathrm{MBE}=\right.$ $\left.-1.6 \mathrm{~W} \mathrm{~m}^{-2}\right)$ and spring $Q_{E}\left(\Delta \mathrm{RMSE}=+0.8 \mathrm{~W} \mathrm{~m}^{-2}\right.$, $\Delta \mathrm{MBE}=-5.8 \mathrm{~W} \mathrm{~m}^{-2}$; Table 2). The summer $Q_{E}$ increased the RMSE $\left(+4.5 \mathrm{~W} \mathrm{~m}^{-2}\right)$ while the $R^{2}$ improved (from 0.08 to 0.15 ) and MBE changed sign (from negative to positive; Table 2). The seasonal mean diurnal cycle shows that the daytime summer $Q_{E}$ is largely overestimated under this irrigation condition (Fig. 9). Irrigation has a very positive impact on modeled $Q_{E}$ in autumn ( $\left.\Delta \mathrm{RMSE}=-7.7 \mathrm{~W} \mathrm{~m}^{-2}, \Delta R^{2}=+0.14\right)$. A sensitivity test of the coefficients $b_{1, m}$ and $b_{2, m}$ (changing from 3 and 1.1 to 2 and 2) amplifies the

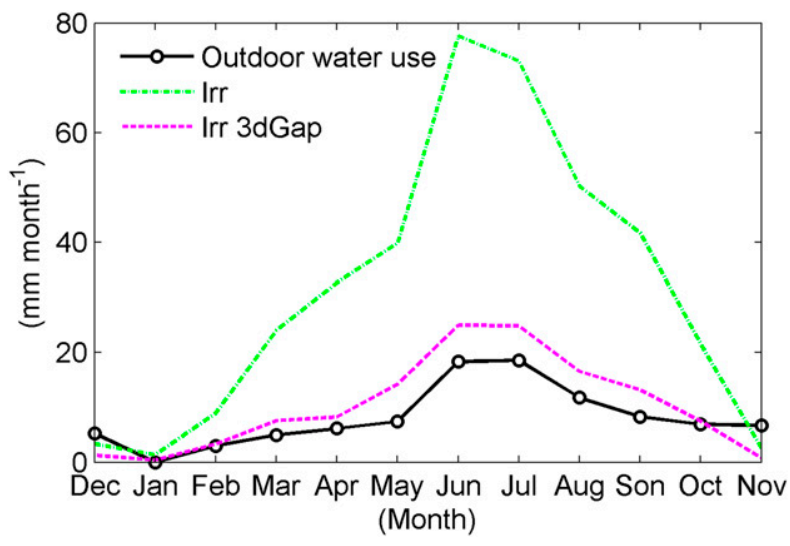

FIG. 8. Monthly outdoor water use observed for the area [section $3 \mathrm{~d}(1)]$ and simulated irrigation.

relative importance of the days after rain, causing a slight decrease in RMSE (not shown).

The trade-off between $Q_{H}$ and $Q_{E}$ is obvious as an overestimation of $Q_{E}$ in summer leads to an underestimation of $Q_{H}$ (Fig. 9). The summer and autumn $Q_{H}$ have an increase in RMSE $\left(+22.7\right.$ and $+0.5 \mathrm{~W} \mathrm{~m}^{-2}$, respectively), but a slight decrease in the other two seasons. The modeled total $Q_{H}$ and $Q_{E}$ remain constant between the Noirr and Irr cases. As the options selected for $\Delta Q_{S}$ coefficients do not change with soil moisture, irrigation also has no impact on modeled $\Delta Q_{S}$ (not shown).

As the second irrigation scenario ( $\left.Q_{F, S} \operatorname{Irr} 3 \mathrm{dGap}\right)$ is less frequent than when irrigation is permitted almost every day except in winter (Fig. 7), the latter annual total irrigation of about $380 \mathrm{~mm}(\sim 30 \%$ of annual rainfall $)$ is much larger than the former $(\sim 140 \mathrm{~mm})$.

From the seasonal mean diurnal cycles of observed and simulated latent heat flux (Fig. 9), the extreme overestimation of $Q_{E}$ under the first irrigation scenario in summer is largely improved, although the diurnal peak is still overestimated with 3-day frequency. The modeled seasonal mean diurnal curves in autumn and spring agree well with the observed curves. The modeled wintertime $Q_{E}$ changes little, as there is only a small amount of irrigation. The $Q_{E}$ RMSE has the largest decrease in summer $\left(-7.7 \mathrm{~W} \mathrm{~m}^{-2}\right)$. The $Q_{H}$ RMSE in spring, summer, and autumn also decreased $(-0.3$, -12.1 , and $-1.5 \mathrm{~W} \mathrm{~m}^{-2}$ ) for the second scenario, but increases slightly $\left(<1 \mathrm{~W} \mathrm{~m}^{-2}\right)$ in winter.

\section{e. Comparison of surface conductance $g_{s}$ among scenarios}

With irrigation turned on, the surface conductance has a substantial increase in July, August, September, and November (Figs. 7d-f). These four months have the least rainfall in summer and autumn (Ao et al. 2016a). 

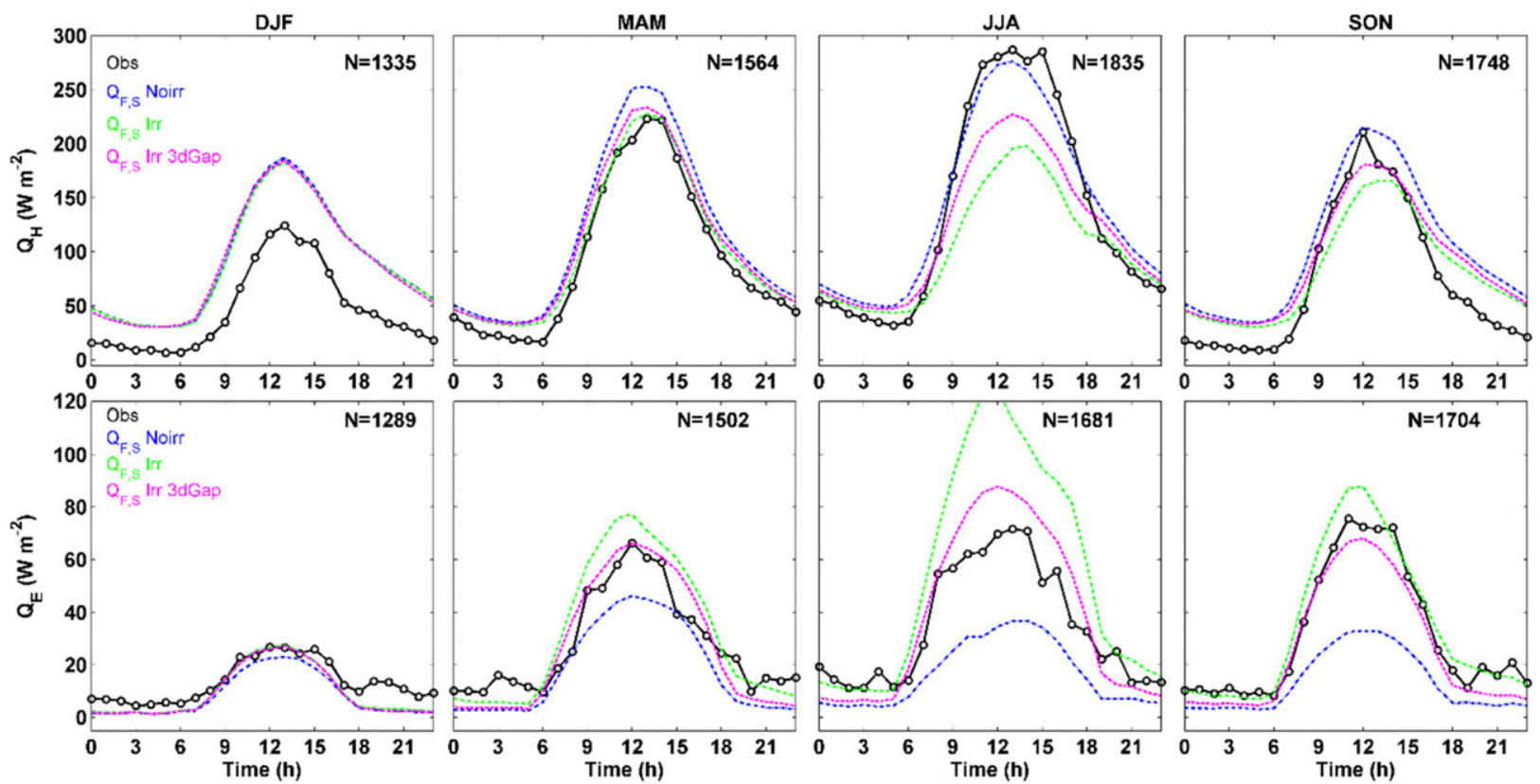

FIG. 9. Seasonal mean diurnal cycles of observed and simulated sensible heat flux $Q_{H}$ and latent heat flux $Q_{E}$ for three irrigation scenarios [defined in section 3d(1)]: $Q_{F, S}$ Noirr, $Q_{F, S}$ Irr, and $Q_{F, S}$ Irr 3dGap. See Figs. C1 and C2 in appendix C for scatterplots.

When irrigation is reduced to every 3 days, the surface conductance in these months still has an obvious increase compared to the no-irrigation scenario, but less than the more frequent irrigation scenario.

Figure 10a shows the monthly median diurnal cycles of $g_{s}$ for different scenarios with the observed $g_{s}$ calculated from the Penman-Monteith equation (Monteith 1965) with observations:

$$
g_{s}^{-1}=r_{s}=\left(\frac{s \beta}{\gamma}-1\right) g_{a}^{-1}+\frac{\rho c_{p} \mathrm{VPD}}{\gamma Q_{E}}
$$

where $\beta$ is the Bowen ratio $\left(\beta=Q_{H} / Q_{E}\right) ; s$ is the slope of the saturation vapor pressure curve $\left(\mathrm{Pa}^{\circ} \mathrm{C}^{-1}\right)$ and is a function of the air temperature; $\gamma$ is the psychrometer constant $\left(\mathrm{Pa}^{\circ} \mathrm{C}^{-1}\right)$ and is determined by air pressure, temperature, and humidity; $\rho$ is the density of air; $c_{p}$ is the specific heat of air at constant pressure; VPD is the vapor pressure deficit which is a function of the air temperature and relative humidity; and $g_{a}$ is the aerodynamic conductance which describes rate of water transport from the air above leaves to the atmosphere at a certain reference height. The term $g_{a}$ is calculated assuming a logarithmic wind profile and therefore is primarily influenced by the wind speed, atmospheric stability, and roughness length for momentum (and the boundary layer resistance is impacted by the roughness length for heat).
Similar to central London (Ward et al. 2016), the diurnal cycle of the observed $g_{s}$ at XJH fluctuates with variable patterns. The monthly median diurnal maximum $g_{s}$ is around $2-4 \mathrm{~mm} \mathrm{~s}^{-1}$. The relatively large $g_{s}$ (both daytime and nighttime) in winter months is somewhat unexpected. This may be caused by the wet winter with still active grass cover and street cleaning activities. The monthly median diurnal aerodynamic conductance $g_{a}$ is regularly sinusoidal in shape with relatively small monthly variations between scenarios. The monthly median $g_{a}$ is much larger than $g_{s}$ (around $12-25 \mathrm{~mm} \mathrm{~s}^{-1}$ ), indicating that evaporation is limited by $g_{s}$ rather than $g_{a}$.

The modeled $g_{s}$ are very different between scenarios. Without irrigation $\left(Q_{F, S}\right.$ Noirr), the $g_{s}$ is totally constrained (near $0 \mathrm{~mm} \mathrm{~s}^{-1}$ ) in July and August. The modeled $g_{s}$ is consistent with observed $g_{s}$ in May, June, and October, but is largely underestimated in winter months. The modeled nocturnal $g_{s}$ is forced to a constant of $0.1 \mathrm{~mm} \mathrm{~s}^{-1}$, which is underestimated through the year. When irrigation is supplied continuously $\left(Q_{F, S} \operatorname{Irr}\right)$, the modeled $g_{s}$ has a substantial increase from May to December and is overestimated during daytime in July and August, which causes the overestimation of $Q_{E}$ in summer. When the irrigation frequency is decreased to every 3 days $\left(Q_{F, S} \operatorname{Irr} 3 \mathrm{dGap}\right)$, the overestimation of $g_{s}$ is improved. The modeled $g_{s}$ during January-April is almost unimpacted by the three scenarios as the irrigation amount is very tiny during this period. 


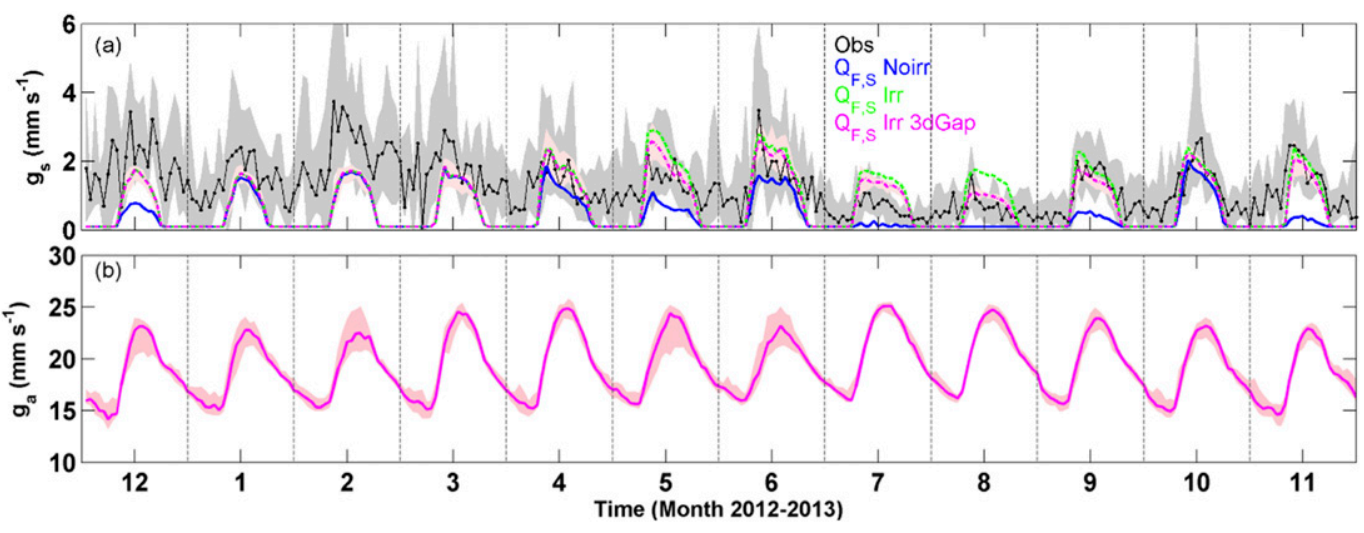

FIG. 10. Monthly median diurnal variation with interquartile range (shading) of (a) observed (black) and modeled (color) surface conductance $g_{s}$ and (b) modeled aerodynamic conductance $g_{a}$.

\section{Discussion and conclusions}

The performance of the urban land surface model SUEWS driven by one year of field measurements is evaluated at a central urban site (XJH) in Shanghai focusing on the estimation and impact of the anthropogenic heat flux $Q_{F}$ and irrigation on the surface energy flux components.

SUEWS estimates $Q_{F}$ as a function of heating and cooling degree days, and scheme coefficients are fitted by results from the inventory-based LQF model. As such, $Q_{F}$ estimates from SUEWS are almost the same as LQF. LQF estimates building $Q_{F B}$, vehicle $Q_{F V}$, and metabolism $Q_{F M}$ components based on city-level hourly electricity consumption data, air temperature, and population density. A new building heat emission-air temperature response function using two balance points made the seasonal variation of the building $Q_{F B}$ more distinct.

The diurnal patterns of $Q_{F B}$ for weekday, weekend, and holidays derived using local electricity data are similar with a peak around 1100 LST. On holidays there is a larger evening peak around 1900 LST. A weekday diurnal profile of $Q_{F V}$ derived from local traffic data has two peaks associated with rush hours. The morning peak is more distinct (at 0800 LST in all seasons) than the evening peak (at 1700 LST). Weekends have no distinct peaks. The largest $Q_{F}$ (estimated by LQF) is in summer with seasonal mean daily peak around $236 \mathrm{Wm}^{-2}$. Winter and autumn have similar mean daily peaks $\left(\sim 190 \mathrm{~W} \mathrm{~m}^{-2}\right)$, and spring is the smallest $\left(\sim 180 \mathrm{~W} \mathrm{~m}^{-2}\right)$. Building heat emission is the largest subcomponent $\left(\sim 95 \%\right.$ of the total $\left.Q_{F}\right)$.

The impact of $Q_{F}$ on surface energy fluxes is explored with (SUEWS, $\left.Q_{F, S}\right)$ and without $Q_{F}\left(Q_{F, 0}\right)$. Ignoring $Q_{F}$, the seasonal diurnal pattern of sensible heat flux $Q_{H}$ is reproduced well generally, but the magnitude of
$Q_{H}$ is underestimated for all seasons. When $Q_{F, S}$ is used, the seasonal mean diurnal $Q_{H}$ is overestimated throughout the day in winter, spring, and autumn. In summer, daytime (nighttime) $Q_{H}$ is slightly underestimated (overestimated). Overall performance for $Q_{H}$ is improved in spring, summer, and autumn (RMSE decreased), but not in winter. For $Q_{F, 0}$, SUEWS summer daytime (nighttime) storage heat flux $\Delta Q_{S}$ is overestimated (underestimated) whereas $Q_{F, S}$ is improved (RMSE decreases by $39 \mathrm{~W} \mathrm{~m}^{-2}$ ). Spring and autumn have improvements (RMSE decreases of 9 and $14 \mathrm{~W} \mathrm{~m}^{-2}$, respectively). But winter does not (RMSE increase of $26 \mathrm{~W} \mathrm{~m}^{-2}$ ). This indicates winter $Q_{F}$ may be overestimated.

Underestimation of $Q_{E}$ is associated with underestimation of the surface conductance $g_{s}$ in summer, mainly caused by large specific humidity deficits. External water supply may maintain evaporation rates. Having the appropriate seasonal cycle of the LAI in winter and spring improve the $Q_{E}$ model performance. Irrigation amount and frequency have a large impact on $Q_{E}$. Seasonal mean summer daytime $Q_{E}$ is largely overestimated if continuous irrigation is permitted, indicating an overestimation of irrigation. In autumn irrigation improves $Q_{E}$ (RMSE decreased, $R^{2}$ increased). Overestimation of $Q_{E}$ with too frequent irrigation in summer is improved when reduced to every 3 days (RMSE decreased), and slightly improved in spring. Reducing irrigation frequency to 3 days also improves summer $Q_{H}$ (RMSE decreased).

This study emphasizes the importance of appropriately estimating the anthropogenic heat flux and external water use in dry and hot seasons in urban land surface models. Previous studies have evaluated SUEWS at two sites (urban and suburban) in the same city or nearby cities with contrasting surface characteristics (Karsisto et al. 2016; 
Ward et al. 2016). Results suggest that the surface cover, especially the vegetated versus impervious proportion along with the anthropogenic heat emission, has the largest impact factor on model performances. The magnitude of $Q_{F}$ may be substantially smaller at suburban sites because of much lower population densities. The difference of building heights at urban and suburban sites will also influence where $Q_{F}$ is released into the atmosphere. Larger vegetated fractions in suburban areas may also have more intensive irrigation. Therefore, future work is inevitably needed to compare simulation results of this central urban site with suburban sites in Shanghai to improve understanding of potential sources of model biases.

Future SUEWS evaluation should consider seasonal variability in the OHM coefficients for the simulation of the storage heat flux $\Delta Q_{S}$. Ward et al. (2016) found adjusting the OHM coefficients for a specific site can significantly improve model performance both for $\Delta Q_{S}$ and for other terms, most notably $Q_{H}$ as the residual term. Seasonal variations of surface properties such as albedo, Bowen ratio, wind speed, and soil moisture (Arnfield and Grimmond 1998; Sun et al. 2017) have critical impacts on $\Delta Q_{S}$. Adjusting OHM coefficients should analyze more observations and use the recently developed analytical objective hysteresis model (AnOHM; Sun et al. 2017) to determine a wider range of parameters.

Acknowledgments. This work was supported by the National Natural Science Foundation of China (Grants 41775019, 41675008), Newton Fund/Met Office Climate Science for Service Partnership (CSSP) China (SG), the Project of Science and Technology Commission of Shanghai Municipality (Grant 17DZ1205300), the Project of Scientific and Technological Development of the Shanghai Meteorological Service (Grant MS201803), and the fund from China Scholarship Council (CSC). We thank everyone who contributed to instrument maintenance, data collection, and model development.

\section{APPENDIX A}

\section{Anthropogenic Heat Flux}

LQF (Gabey et al. 2018) is a new implementation of the Large Scale Urban Consumption of Energy (LUCY) model (Allen et al. 2011; Lindberg et al. 2013). LQF (short for LUCY QF) is embedded in the Urban Multiscale Environmental Predictor (UMEP), which is an open-source, city-based climate service tool that combines models and tools for climate simulations (Lindberg et al. 2018). LQF takes a "top down" approach, using publicly available annual energy consumption data for a large area (e.g., country, province, city) with high-resolution population density data to distribute the energy consumption across the area of interest. It separately considers three emission sources: buildings $Q_{F B}$, traffic $Q_{F V}$, and metabolism $Q_{F M}$ (Grimmond 1992; Sailor 2011). Like the SUEWS method, the daily totals are a function of temperatures (temperature response function) and subdaily patterns are based on diurnal use profiles.

\section{a. LQF temperature response function}

Variations of energy consumption with air temperature can be modeled with a single balance point temperature $T_{b}$ [Eq. (2)] obtained from when the energy consumption is lowest. Consequently, $T_{b}$ varies with climate (Amato et al. 2005) and/or with building type. Therefore, it is preferable to have the appropriate local $T_{b}$ as it has a large impact on seasonal variations of the building anthropogenic heat emissions. This approach is used in $Q_{F}, S$ (SUEWS) and was originally used in LQF $\left(Q_{F}, L\right)$. In this work we introduced a new LQF temperature response function (Fig. 2) with two balance point temperatures, that is, threshold temperatures when heating $T_{h}$ and cooling $T_{c}$ commence.

To quantify $T_{b}$ for Shanghai, the whole city electricity consumption (Liu and Cao 2013) and XJH air temperature data are analyzed (Fig. 2b). Ideally, all sources of energy would be analyzed, but electricity consumption data are often used as a proxy for building heat release. For example, Kikegawa et al. (2014) estimate that in Tokyo $\sim 80 \%$ of office building energy demand in summer is from electricity consumption. The buildings in the $\mathrm{XJH}$ area are predominately office and residential buildings, with very little industry. Shanghai Municipal Statistics Bureau (2016) indicates industry around the dense urban XJH site $\left(f_{\text {inu }}\right)$ accounts for about $10 \%$ of total energy consumption. In contrast, suburban districts such as Jiading have a much higher industry fraction.

Given the similar climatic regime, building energy consumption at our study site is assumed to be like Tokyo. However, Shanghai's electricity consumption is only $14 \%$ of the total energy consumption (Table A1). As industry consumption is relatively insensitive to weather conditions (Sailor 2011), it has a different profile to the commercial study site of interest, with reduced daily amplitude and seasonal variations. Given the difficulty of accessing details of industrial consumption patterns, for simplicity the industrial load is assumed to be uniform through the day (Sailor 2011). 
TABLE A1. Energy consumption in Shanghai (Shanghai Municipal Statistics Bureau 2016) in ton coal equivalent (TCE) is converted to kilowatt hours assuming $1 \mathrm{TCE}=8141 \mathrm{kWh}($ Kyle's Converter 2017).

\begin{tabular}{|c|c|c|c|c|c|c|c|}
\hline \multirow[b]{2}{*}{ Year } & \multicolumn{2}{|c|}{$\begin{array}{l}\text { Energy consumption } 10^{4} \\
\text { TCE }\end{array}$} & \multicolumn{2}{|c|}{$\begin{array}{c}\text { Electricity } \\
\text { consumption } 100 \\
\text { million kWh }\end{array}$} & \multirow{2}{*}{$\begin{array}{c}\text { Electricity consumption } \\
10^{4} \text { tons } S C E\end{array}$} & \multirow[b]{2}{*}{$f_{\text {ele }}$} & \multirow[b]{2}{*}{$N_{\text {pop }} 10^{4}$ persons } \\
\hline & Total & Industry & Total & Industry & & & \\
\hline 2005 & 7974.24 & 4863.17 & 921.97 & 617.59 & 1133.10 & 0.1421 & 1890.26 \\
\hline 2006 & 8604.89 & 5152.05 & 990.15 & 656.1 & 1216.89 & 0.1414 & 1964.11 \\
\hline 2007 & 9374.6 & 5452.95 & 1072.38 & 705.9 & 1317.96 & 0.1406 & 2063.58 \\
\hline 2008 & 9894.52 & 5598.41 & 1138.22 & 727.13 & 1398.87 & 0.1414 & 2140.65 \\
\hline 2009 & 10050.06 & 5465.53 & 1153.38 & 701.59 & 1417.50 & 0.1410 & 2210.28 \\
\hline 2013 & 11345.69 & 6009.41 & 1410.61 & 799.45 & 1733.64 & 0.1528 & 2415.27 \\
\hline
\end{tabular}

The relation between energy consumption and air temperature is analyzed. In Shanghai, the energy consumption rises almost linearly when the daily mean air temperature is warmer than $21^{\circ} \mathrm{C}$ or cooler than $15^{\circ} \mathrm{C}$, providing evidence that cooling or heating systems are operating in these temperature ranges (Fig. 2b). In the "comfortable" range $\left(15^{\circ}-21^{\circ} \mathrm{C}\right)$ energy consumption stays nearly constant. The energy consumption for cooling increases more rapidly than for heating as central heating systems are absent south of an east-west (Qin-Huai) line near $33^{\circ} \mathrm{N}$ (Makinen 2014; Shi et al. 2016). Given this in SUEWS, a single $T_{b}$ of $20^{\circ} \mathrm{C}$ is used.

In LQF the three components of $Q_{F}$ (building, transport, metabolism) are treated separately. A temperature response function $f_{b}$ modifies the base daily building energy consumption $E_{B, b}\left(\mathrm{kWh}\right.$ day ${ }^{-1}$ per capita):

$$
Q_{F, b L, \text { daily }}=\rho_{\text {pop }} f_{b} E_{B, b} \text {, }
$$

where $\rho_{\text {pop }}$ is the population density of $\mathrm{XJH}$ site $\left(N_{\text {pop }}=261.62\right.$ capita $\left.\mathrm{ha}^{-1}\right)$. Here the original LQF one balance point temperature function (Allen et al. 2011; Lindberg et al. 2013; Fig. 2b, dotted line) is modified to allow minimum energy consumption to occur over a range of temperatures. Threshold temperatures when heating $T_{h}$ and cooling $T_{c}$ ) commence, and when saturation energy use occurs as additional energy consumption is minimal (Fig. 2a, solid line); that is, $<T_{\min }$ no additional heating occurs $\left(>T_{\max }\right.$ for cooling). Therefore, logic variables $\left(l_{c 1}, l_{h 1}\right)$ are 0 except when the air temperature is with a critical range (Fig. 2b):

$$
\begin{array}{ll}
T_{\max }>T_{a}>T_{c}, & l_{c 1}=1, \\
T_{\min }<T_{a}<T_{h}, & l_{h 1}=1,
\end{array}
$$

to allow

$$
f_{b}=b_{b}+A_{c}\left|T_{a}-T_{c}\right| l_{c 1}+A_{h}\left|T_{a}-T_{h}\right| l_{h 1} .
$$

Or more completely,

$f_{b}=b_{b}+A_{c}\left|T_{a}-T_{c}\right| l_{c 1}+A_{h}\left|T_{a}-T_{h}\right| l_{h 1}+l_{h 2} b_{h}+l_{c 2} b_{c}$,

with two logic variables $\left(l_{c 2}, l_{h 2}\right)$ which are nonzero when

$$
T_{a} \geq T_{\max }, \quad l_{c 2}=1 \quad \text { or } \quad T_{a} \leq T_{\min }, \quad l_{h 2}=1 .
$$

The three nondimensional coefficients $b_{b}, b_{c}$, and $b_{h}$ are the base fraction of energy use when small changes in daily air temperature have no impact. The comfortable air temperature ranges (i.e., between $T_{h}$ and $T_{c}$ ) for $b_{b}$ and then once all heating $b_{h}$ or cooling $b_{c}$ are on. Variables $A_{c}$ and $A_{h}$ are the building energy consumption thermal response slopes for cooling (heating) when daily air temperature warmer (colder) than $T_{c}\left(T_{h}\right)$.

To determine the parameter values for Shanghai, the 2005-09 city-wide electricity consumption data (Liu and Cao 2013) are used (Fig. 2b). The resulting parameters are $b_{b}=0.88, A_{c}=0.04^{\circ} \mathrm{C}^{-1}$, and $A_{h}=$ $0.01^{\circ} \mathrm{C}^{-1}$. In this subtropical city, the larger cooling coefficient $A_{c}$ reflects the absence of a centralized heating system in Shanghai but extensive use of air conditioning in summer.

\section{b. Vehicle based heat emissions}

The heat released by motor vehicles $Q_{F V}$ from combustion of petrol or diesel fuel (Sailor 2011) generally does not have seasonal variations (Sailor and Lu 2004). In LQF, $Q_{F V}$ is calculated as a function of vehicle numbers $($ cars $=89$, motorcycles $=17.2$, freight vehicles $=8.8$ per 1000 capita; Shanghai Municipal Statistics Bureau 2016), traffic speed, and time (days, hour). The fuel type is assumed to be petrol (Zhao 2007). The mean vehicle speed is set to $48 \mathrm{~km} \mathrm{~h}^{-1}$ ( Su et al. 2014). 

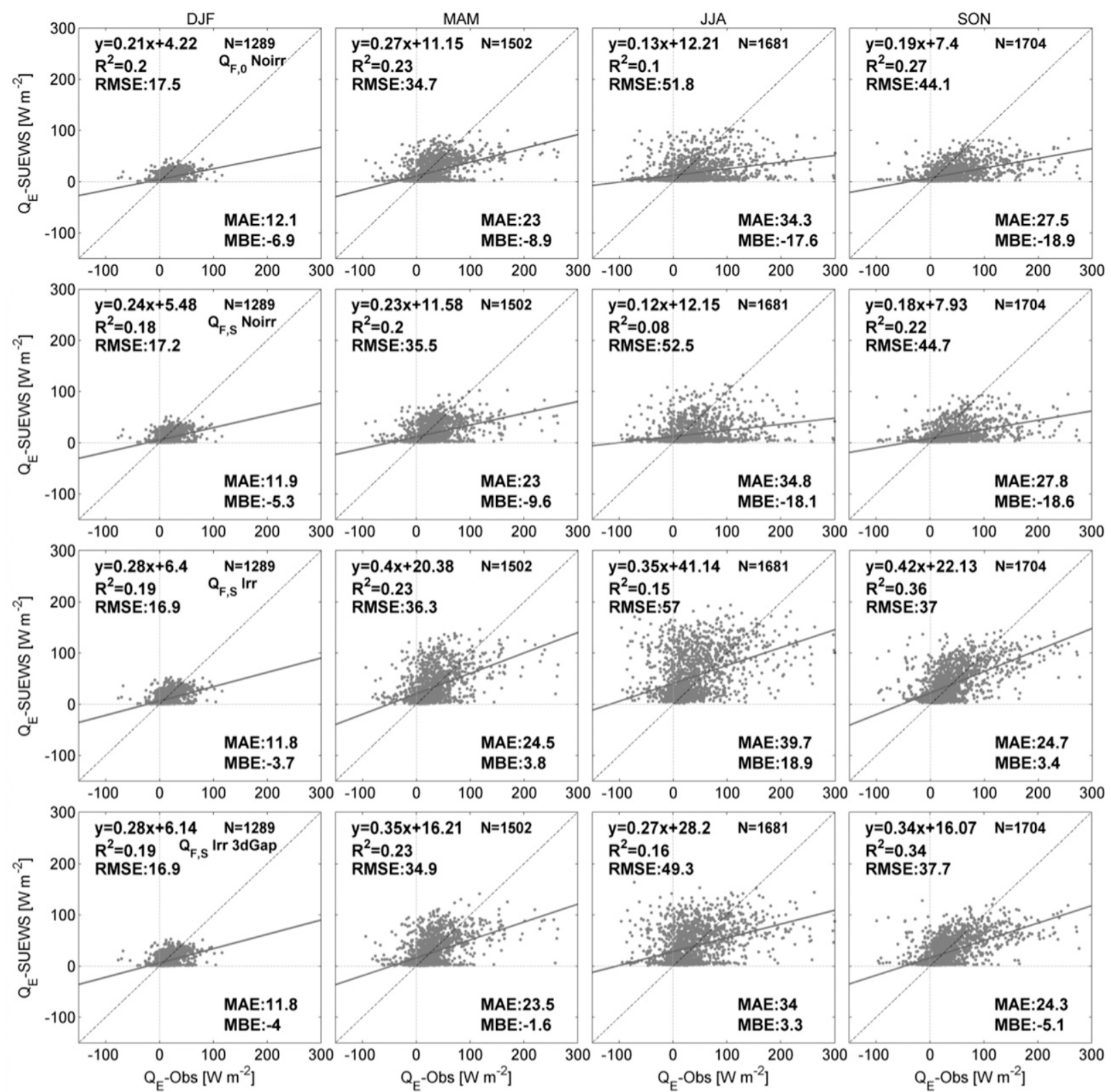

FIG. C1. Simulated vs observed latent heat flux $Q_{E}$ for each experiment $\left(Q_{F, 0}\right.$ Noirr $Q_{F, S}$ Noirr, $\left.Q_{F, S} \operatorname{Irr}, Q_{F, S} \operatorname{Irr} 3 \mathrm{dGap}\right)$. Statistics shown are $R^{2}$, RMSE, MAE, and MBE.

Hourly highway traffic data (traffic count and speed) for the inner ring of Shanghai in 2011 are used to derive the diurnal profiles for weekdays, weekends, and holidays (Fig. 3b). These are applied to all roads in the study area (see section $3 a$ ).

\section{c. Population density}

In LQF, the default population is from the Gridded Population of the World, version 4 (GPWv4; CIESIN 2017), with estimates for 2005, 2010, and 2015. The 2010
30 -arc-s $(\sim 1 \mathrm{~km})$ population density around the $\mathrm{XJH}$ site is about 261.62 capita $^{-1}$ (CIESIN 2017), whereas the statistics in 2013 (Shanghai Municipal Statistics Bureau of Xuhui District 2013) for the XJH site neighborhood $\left(4.07 \mathrm{~km}^{2}\right)$ have a permanent resident population of 92764 (i.e., 227.92 capita $\mathrm{ha}^{-1}$ ). Here the population density of 261.62 capita ha $^{-1}$ is used as the resolution is closer to the source area of $\mathrm{XJH}$ site.

Urban population density varies significantly through the course of a day and from working days to nonworking 

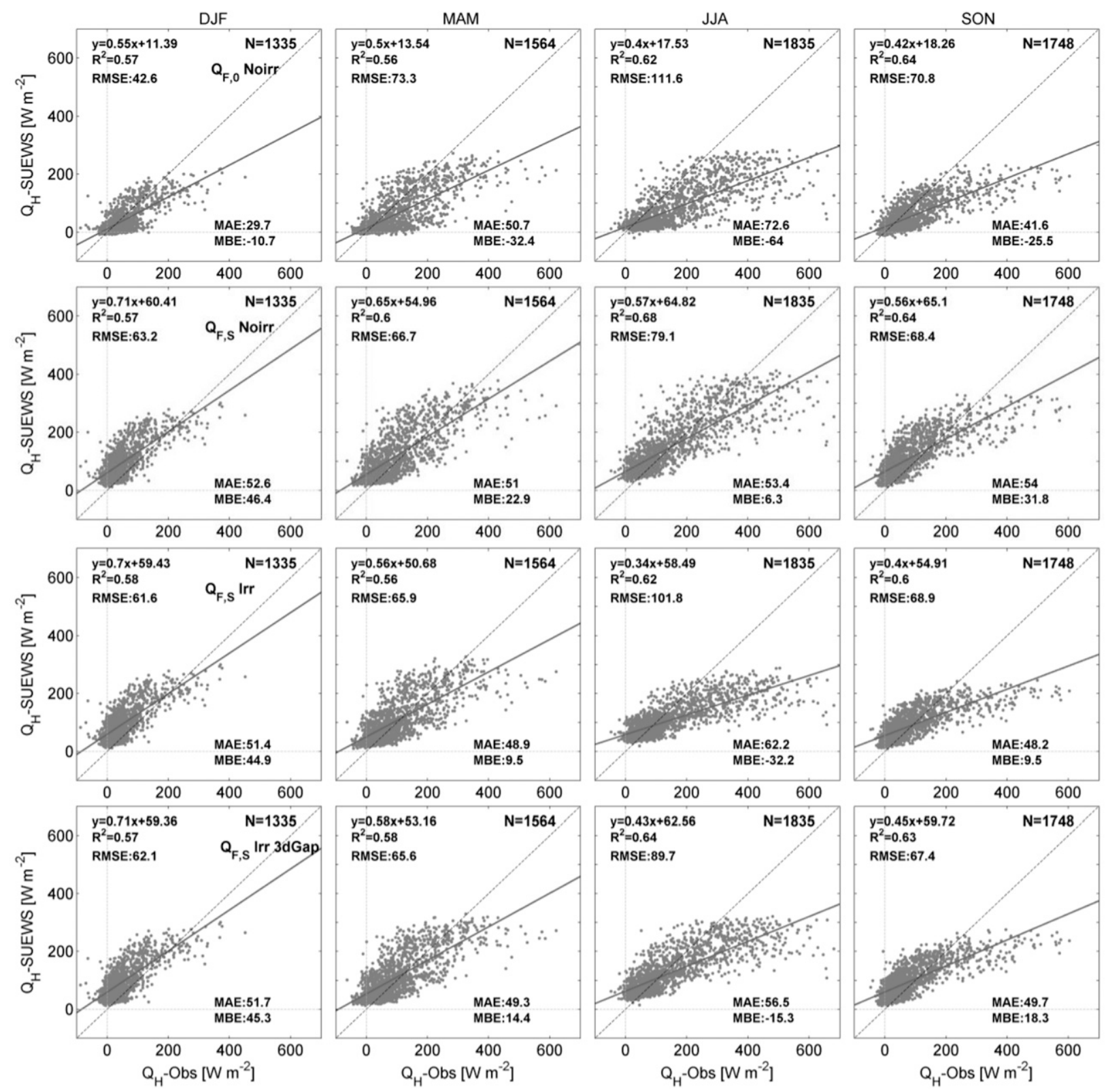

FIG. C2. As in Fig. C1, but for sensible heat flux $Q_{H}$.

days (Gabey et al. 2018), particularly in areas such as XJH with a mix of permanent residents, shoppers, tourists, hospital visitors and patients, etc. who come and go. The publicly available data from the national census of Shanghai do not capture these dynamics. Yu and Wen (2016) estimate daytime and nighttime population for the Jing'an district using land use and population age structure data. They suggest the daytime population is $39.2 \%$ higher than at night for the district as a whole (and $147.7 \%$ higher in the busiest subdistrict). W. Zhong et al.'s (2017) analysis of cell phone signals found from 0600 to 1000 LST people move into the center of Shanghai from outer areas, with a peak at 1000 LST that is sustained until 1800 LST, when the return to suburban areas occurs. The day-to-night population density ratio in central Shanghai is about 1.5 (W. Zhong et al. 2017, their Fig. 7). Based on these two studies, the daytime (1000-1800 LST) population is assumed to be 1.5 times the nocturnal population at $\mathrm{XJH}$ site, with the periods $0600-1000$ and 1800-2200 LST being transition periods when the population moves between work, leisure, and residential sites [a linear increase (decrease) is assumed, following Sailor and Lu (2004)]. Using this dynamic ratio, and assuming the daytime and nocturnal 

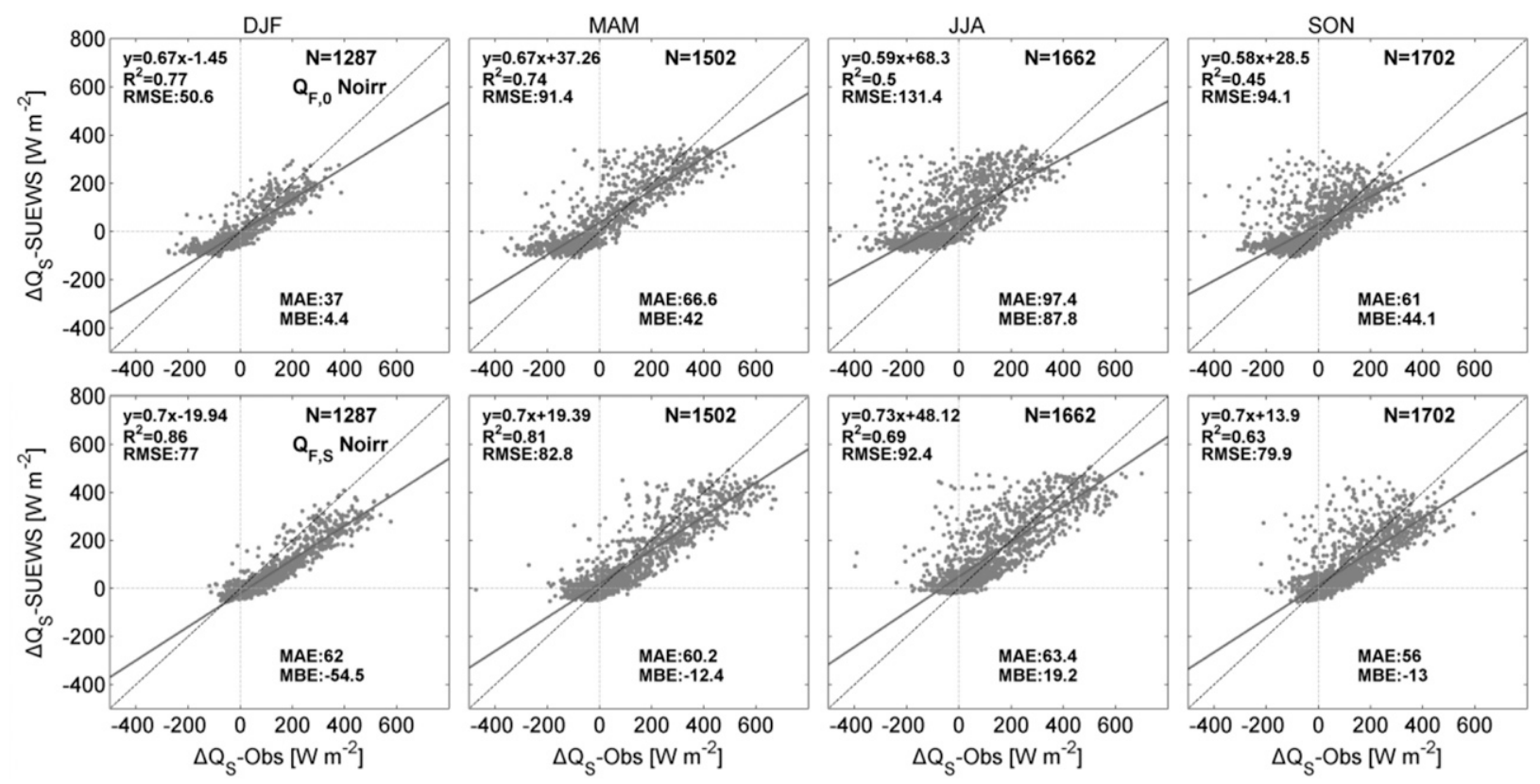

FIG. C3. As in Fig. C1, but for storage heat flux $\Delta Q_{s}$. As OHM coefficients varying with soil moisture are not used, irrigation has no influence on $\Delta Q_{S}$, so the results of related experiments are not shown.

population for the whole Shanghai is roughly conserved, the diurnal variation of the electricity consumption is further scaled.

\section{APPENDIX B}

\section{Statistical Evaluation Techniques}

Common statistical metrics are used to assess model performance. The modeled $M_{i}$ and observed $O_{i}$ values are used with their corresponding mean values $\bar{M}, \bar{O}$ to calculate the coefficient of determination $R^{2}$,

$$
R^{2}=\left[\frac{\sum_{i=1}^{N}\left(M_{i}-\bar{M}\right)\left(O_{i}-\bar{O}\right)}{\sqrt{\sum_{i=1}^{N}\left(M_{i}-\bar{M}\right)^{2}} \sqrt{\sum_{i=1}^{N}\left(O_{i}-\bar{O}\right)^{2}}}\right]^{2} ;
$$

the root-mean-square error (RMSE),

$$
\text { RMSE }=\sqrt{\frac{1}{N} \sum_{i=1}^{N}\left(M_{i}-O_{i}\right)^{2}} ;
$$

mean bias error (MBE),

$$
\mathrm{MBE}=\frac{1}{N} \sum_{i=1}^{N}\left(M_{i}-O_{i}\right)
$$

and the mean absolute error (MAE),

$$
\operatorname{MAE}=\frac{1}{N} \sum_{i=1}^{N}\left|M_{i}-O_{i}\right|
$$

The RMSE, MBE, and MAE all have units of the variable analyzed and an ideal value of 0 ; whereas $R^{2}$ varies between 0 and 1 with an ideal value of 1 .

\section{APPENDIX C}

\section{Simulated versus Observed Fluxes}

Figs. C1-C3 illustrate simulated versus observed fluxes for each experiment.

\section{REFERENCES}

Alexander, P. J., G. Mills, and R. Fealy, 2015: Using LCZ data to run an urban energy balance model. Urban Climate, 13, 14-37, https://doi.org/10.1016/j.uclim.2015.05.001.

Allen, L., F. Lindberg, and C. S. B. Grimmond, 2011: Global to city scale urban anthropogenic heat flux: Model and variability. Int. J. Climatol., 31, 1990-2005, https://doi.org/10.1002/joc.2210.

Amato, A. D., M. Ruth, P. Kirshen, and J. Horwitz, 2005: Regional energy demand responses to climate change: Methodology and application to the Commonwealth of Massachusetts. Climatic Change, 71, 175-201, https://doi.org/10.1007/s10584-005-5931-2.

Anandakumar, K., 1999: A study on the partition of net radiation into heat fluxes on a dry asphalt surface. Atmos. Environ., 33, 3911-3918, https://doi.org/10.1016/S1352-2310(99)00133-8.

Ao, X., and Coauthors, 2016a: Heat, water and carbon exchanges in the tall megacity of Shanghai: Challenges and results. Int. J. Climatol., 36, 4608-4624, https://doi.org/10.1002/joc.4657. 
- C. S. B. Grimmond, D. Liu, Z. Han, P. Hu, Y. Wang, X. Zhen, and J. Tan, 2016b: Radiation fluxes in a business district of Shanghai, China. J. Appl. Meteor. Climatol., 55, 2451-2468, https://doi.org/10.1175/JAMC-D-16-0082.1.

Arnfield, A. J., and C. S. B. Grimmond, 1998: An urban canyon energy budget model and its application to urban storage heat flux modeling. Energy Build., 27, 61-68, https://doi.org/10.1016/ S0378-7788(97)00026-1.

Asaeda, T., and V. Ca, 1993: The subsurface transport of heat and moisture and its effect on the environment: A numerical model. Bound.-Layer Meteor., 65, 159-179, https://doi.org/ 10.1007/BF00708822.

Best, M. J., and C. S. B. Grimmond, 2016a: Investigation of the impact of anthropogenic heat flux within an urban land surface model and PILPS-urban. Theor. Appl. Climatol., 126, 51-60, https://doi.org/10.1007/s00704-015-1554-3.

— fluxes at urban sites with varying vegetation cover. $J$. $H y$ drometeor., 17, 2537-2553, https://doi.org/10.1175/JHM-D-150126.1.

Chang, Y., J. Tan, J. Peng, and W. Gu, 2015: Relativity analysis of daily water supply and meteorology factor and establishment of forecast model in Shanghai (in Chinese). J. Water Resour. Water Eng., 26, 32-36, https://doi.org/ 10.11705/j.issn.1672-643X.2015.01.006.

Chen, F., and Coauthors, 2011: The integrated WRF/urban modeling system: Development, evaluation, and applications to urban environmental problems. Int. J. Climatol., 31, 273-288, https://doi.org/10.1002/joc.2158.

— X. Yang, and J. Wu, 2016: Simulation of the urban climate in a Chinese megacity with spatially heterogeneous anthropogenic heat data. J. Geophys. Res. Atmos., 121, 5193-5212, https://doi.org/10.1002/2015JD024642.

Chen, L., M. Zhang, and Y. Wang, 2016: Model analysis of urbanization impacts on boundary layer meteorology under hot weather conditions: A case study of Nanjing, China. Theor. Appl. Climatol., 125, 713-728, https://doi.org/10.1007/ s00704-015-1535-6.

Chow, W. T., F. Salamanca, M. Georgescu, A. Mahalov, J. M. Milne, and B. L. Ruddell, 2014: A multi-method and multiscale approach for estimating city-wide anthropogenic heat fluxes. Atmos. Environ., 99, 64-76, https://doi.org/10.1016/ j.atmosenv.2014.09.053.

Christen, A., and R. Vogt, 2004: Energy and radiation balance of a central European city. Int. J. Climatol., 24, 1395-1421, https:// doi.org/10.1002/joc.1074.

CIESIN, 2017: Gridded Population of the World (GPW), v4. Subset used: Population Density, v4.10, NASA SEDAC, accessed 28 November 2018, https://doi.org/10.7927/H4DZ068D.

Coutts, A. M., N. J. Tapper, J. Beringer, M. Loughnan, and M. Demuzere, 2013: Watering our cities: The capacity for water sensitive urban design to support urban cooling and improve human thermal comfort in the Australian context. Prog. Phys. Geogr., 37, 2-28, https://doi.org/10.1177/ 0309133312461032.

Demuzere, M., A. M. Coutts, M. Göhler, A. M. Broadbent, H. Wouters, N. P. M. van Lipzig, and L. Gebert, 2014: The implementation of biofiltration systems, rainwater tanks and urban irrigation in a single-layer urban canopy model. Urban Climate, 10,148-170, https://doi.org/10.1016/ j.uclim.2014.10.012.

— , and Coauthors, 2017: Impact of urban canopy models and external parameters on the modelled urban energy balance in a tropical city. Quart. J. Roy. Meteor. Soc., 143, 1581-1596, https://doi.org/10.1002/qj.3028.

Ding, A., and Coauthors, 2016: Enhanced haze pollution by black carbon in megacities in China. Geophys. Res. Lett., 43, 2873 2879, https://doi.org/10.1002/2016GL067745.

Doll, D., J. K. S. Ching, and J. Kaneshiro, 1985: Parameterization of subsurface heating for soil and concrete using net radiation data. Bound.-Layer Meteor., 32, 351-372, https://doi.org/10.1007/ BF00122000.

Feng, J. M., Y. L. Wang, Z. G. Ma, and Y. H. Liu, 2012: Simulating the regional impacts of urbanization and anthropogenic heat release on climate across China. J. Climate, 25, 7187-7203, https://doi.org/10.1175/JCLI-D-11-00333.1.

Fuchs, M., and A. Hadas, 1972: The heat flux density in a nonhomogeneous bare loessial soil. Bound.-Layer Meteor., 3, 191200, https://doi.org/10.1007/BF02033918.

Gabey, A., S. Grimmond, and I. Capel-Timms, 2018: Anthropogenic heat flux: Advisable spatial resolutions when input data are scarce. Theor. Appl. Climatol., https://doi.org/10.1007/ s00704-018-2367-y, in press.

Grimmond, C. S. B., 1992: The suburban energy balance: Methodological considerations and results for a mid-latitude west coast city under winter and spring conditions. Int. J. Climatol., 12, 481-497, https://doi.org/10.1002/joc.3370120506.

_ _ and T. R. Oke, 1986: Urban water-balance: 2. Results from a suburb of Vancouver, British-Columbia. Water Resour. Res., 22, 1404-1412, https://doi.org/10.1029/WR022i010p01404.

—, and _- 1991: An evaporation-interception model for urban areas. Water Resour. Res., 27, 1739-1755, https://doi.org/ 10.1029/91WR00557.

— , and - 1999: Heat storage in urban areas: Local-scale observations and evaluation of a simple model. J. Appl. Meteor. Climatol., 38, 922-940, https://doi.org/10.1175/1520-0450 (1999) $038<0922: H S I U A L>2.0 . C O ; 2$.

- H. A. Cleugh, and T. R. Oke, 1991: An objective urban heat storage model and its comparison with other schemes. Atmos. Environ., 25, 311-326, https://doi.org/10.1016/0957-1272(91) 90003-W.

_ - and Coauthors, 2010: The International Urban Energy Balance Models Comparison Project: First results from phase 1. J. Appl. Meteor. Climatol., 49, 1268-1292, https://doi.org/ 10.1175/2010JAMC2354.1.

_ - and Coauthors, 2011: Initial results from phase 2 of the international urban energy balance model comparison. Int. J. Climatol., 31, 244-272, https://doi.org/10.1002/joc.2227.

Guo, W., X. Wang, J. Sun, A. Ding, and J. Zou, 2016: Comparison of land-atmosphere interaction at different surface types in the mid- to lower reaches of the Yangtze river valley. Atmos. Chem. Phys., 16, 9875-9890, https://doi.org/ 10.5194/acp-16-9875-2016.

Hallenbeck, M., M. Rice, B. Smith, C. Cornell-Martinez, and J. Wilkinson, 1997: Vehicle volume distribution by classification. Washington State Transportation Center, 54 pp.

Ichinose, T., K. Shimodozono, and K. Hanaki, 1999: Impact of anthropogenic heat on urban climate in Tokyo. Atmos. Environ., 33, 3897-3909, https://doi.org/10.1016/S1352-2310(99) 00132-6.

Järvi, L., C. S. B. Grimmond, and A. Christen, 2011: The surface urban energy and water balance scheme (SUEWS): Evaluation in Los Angeles and Vancouver. J. Hydrol., 411, 219-237, https://doi.org/10.1016/j.jhydrol.2011.10.001.

, M. Taka, A. Nordbo, H. Setälä, and I. B. Strachan, 2014: Development of the Surface Urban Energy and Water balance 
Scheme (SUEWS) for cold climate cities. Geosci. Model Dev. 7, 1691-1711, https://doi.org/10.5194/gmd-7-1691-2014.

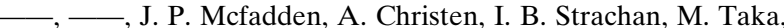
L. Warsta, and M. Heimann, 2017: Warming effects on the urban hydrology in cold climate regions. Sci. Rep., 7, 5833, https://doi.org/10.1038/s41598-017-05733-y.

Jarvis, P. G., 1976: The interpretation of the variations in leaf water potential and stomatal conductance found in canopies in the field. Philos. Trans. Roy. Soc. London, 273B, 593-610, https:// doi.org/10.1098/rstb.1976.0035.

Jiang, Y., X.-Q. Yang, and X. Liu, 2015: Seasonality in anthropogenic aerosol effects on East Asian climate simulated with CAM5. J. Geophys. Res. Atmos., 120, 10837-10861, https:// doi.org/10.1002/2015JD023451.

Kanda, M., A. Inagaki, T. Miyamoto, M. Gryschka, and S. Raasch, 2013: A new aerodynamic parametrization for real urban surfaces. Bound.-Layer Meteor., 148, 357-377, https://doi.org/ 10.1007/s10546-013-9818-x.

Karsisto, P., C. Fortelius, M. Demuzere, C. S. B. Grimmond, K. W Oleson, R. Kouznetsov, V. Masson, and L. Järvi, 2016: Seasonal surface urban energy balance and wintertime stability simulated using three land-surface models in the high-latitude city Helsinki. Quart. J. Roy. Meteor. Soc., 142, 401-417, https:// doi.org/10.1002/qj.2659.

Kent, C. W., S. Grimmond, J. Barlow, D. Gatey, S. Kotthaus, F. Lindberg, and C. H. Halios, 2017: Evaluation of urban localscale aerodynamic parameters: Implications for the vertical profile of wind speed and for source areas. Bound.-Layer Meteor., 164, 183-213, https://doi.org/10.1007/s10546-017-0248-z.

Khatun, R., and Coauthors, 2011: Spatial variations in evapotranspiration over East Asian forest sites. I. Evapotranspiration and decoupling coefficient. Hydrol. Res. Lett., 5, 83-87, https://doi.org/10.3178/hrl.5.83.

Kikegawa, Y., A. Tanaka, Y. Ohashi, T. Ihara, and Y. Shigeta, 2014: Observed and simulated sensitivities of summertime urban surface air temperatures to anthropogenic heat in downtown areas of two Japanese major cities, Tokyo and Osaka. Theor. Appl. Climatol., 117, 175-193, https://doi.org/ 10.1007/s00704-013-0996-8.

Kljun, N. P., P. Calanca, M. V. Rotach, and H. P. Schmid, 2004: A simple parameterisation for flux footprint predictions. Bound.-Layer Meteor., 112, 503-523, https://doi.org/10.1023/ B:BOUN.0000030653.71031.96.

Kokkonen, T. V., C. S. B. Grimmond, O. Räty, H. C. Ward, A. Christen, T. R. Oke, S. Kotthaus, and L. Järvi, 2018: Sensitivity of Surface Urban Energy and Water Balance Scheme (SUEWS) to downscaling of reanalysis forcing data. Urban Climate, 23, 36-52, https://doi.org/10.1016/j.uclim.2017.05.001.

Kotthaus, S., and C. S. B. Grimmond, 2014: Energy exchange in a dense urban environment - Part I: Temporal variability of long-term observations in central London. Urban Climate, 10, 261-280, https://doi.org/10.1016/j.uclim.2013.10.002.

Kusaka, H., H. Kondo, Y. Kikegawa, and F. Kimura, 2001: A simple single-layer urban canopy model for atmospheric models: Comparison with multi-layer and slab models. Bound.-Layer Meteor., 101, 329-358, https://doi.org/10.1023/ A:1019207923078.

Kyle's Converter, 2017: Convert tons of coal equivalent to kilowatt-hours. Kyle's Converter, accessed 1 December 2017, http://www.kylesconverter.com/energy,-work,-and-heat/tonsof-coal-equivalent-to-kilowatt--hours.

Li, D., T. Sun, M. Liu, L. Yang, L. Wang, and Z. Gao, 2015: Contrasting responses of urban and rural surface energy budgets to heat waves explain synergies between urban heat islands and heat waves. Environ. Res. Lett., 10, 054009, https://doi.org/ 10.1088/1748-9326/10/5/054009.

Lindberg, F., C. S. B. Grimmond, N. Yogeswaran, S. Kotthaus, and L. Allen, 2013: Impact of city changes and weather on anthropogenic heat flux in Europe 1995-2015. Urban Climate, 4, 1-15, https://doi.org/10.1016/j.uclim.2013.03.002.

and Coauthors, 2018: Urban multiscale environmental predictor (UMEP) - An integrated tool for city-based climate services. Environ. Modell. Software, 99, 70-87, https://doi.org/ 10.1016/j.envsoft.2017.09.020.

Liu, H., and L. Cao, 2013: The relationship between power load and meteorological factors with refined power load forecast in Shanghai (in Chinese). J. Appl. Meteor. Sci., 24, 455-463.

Loridan, T., C. S. B. Grimmond, B. D. Offerle, D. T. Young, T. E. L. Smith, L. Järvi, and F. Lindberg, 2011: Local-scale Urban Meteorological Parameterization Scheme (LUMPS): Longwave radiation parameterization and seasonality-related developments. J. Appl. Meteor. Climatol., 50, 185-202, https:// doi.org/10.1175/2010JAMC2474.1.

, F. Lindberg, O. Jorba, S. Kotthaus, S. Grossman-Clarke, and C. S. B. Grimmond, 2013: High resolution simulation of surface heat flux variability across central London with urban zones for energy partitioning. Bound.-Layer Meteor., 147, 493-523, https://doi.org/10.1007/s10546-013-9797-y.

Lu, Y., Q. Wang, Y. Zhang, P. Sun, and Y. Qian, 2016: An estimate of anthropogenic heat emissions in China. Int. J. Climatol., 36, 1134-1142, https://doi.org/10.1002/joc.4407.

Makinen, J., 2014: For central heat, China has a north-south divide at Qin-Huai line. Los Angeles Times, 15 November, http:// www.latimes.com/world/asia/la-fg-china-heat-20141115-story. html.

Masson, V., and Coauthors, 2013: The SURFEXv7.2 land and ocean surface platform for coupled or offline simulation of earth surface variables and fluxes. Geosci. Model Dev., 6, 929960, https://doi.org/10.5194/gmd-6-929-2013.

Matsumoto, K., and Coauthors, 2008: Responses of surface conductance to forest environments in the Far East. Agric. For. Meteor., 148, 1926-1940, https://doi.org/ 10.1016/j.agrformet.2008.09.009.

McCaughey, J. H., 1985: Energy balance storage terms in a mature mixed forest at Petawawa, Ontario-A case study. Bound.-Layer Meteor., 31, 89-101, https://doi.org/10.1007/ BF00120036.

McMaster, G. S., and W. W. Wilhelm, 1997: Growing degree-days: One equation, two interpretations. Agric. For. Meteor., 87, 291-300, https://doi.org/10.1016/S0168-1923(97)00027-0.

Meyn, S. K., 2001: Heat fluxes through roofs and their relevance to estimates of urban heat storage. Ph. D. dissertation, University of British Columbia, 118 pp.

Miao, S. G., and F. Chen, 2014: Enhanced modeling of latent heat flux from urban surfaces in the Noah/single-layer urban canopy coupled model. Sci. China Earth Sci., 57, 2408-2416, https://doi.org/10.1007/s11430-014-4829-0.

Mitchell, V. G., R. G. Mein, and T. A. Mcmahon, 2001: Modelling the urban water cycle. Environ. Modell. Software, 16, 615-629, https://doi.org/10.1016/S1364-8152(01)00029-9.

, H. A. Cleugh, C. S. B. Grimmond, and J. Xu, 2008: Linking urban water balance and energy balance models to analyse urban design options. Hydrol. Processes, 22, 2891-2900, https://doi.org/10.1002/hyp.6868.

Monteith, J. L., 1965: Evaporation and environment. Symp. Soc. Exp. Biol., 19, 205-224. 
Nakayoshi, M., R. Moriwaki, T. Kawai, and M. Kanda, 2009: Experimental study on rainfall interception over an outdoor urban-scale model. Water Resour. Res., 45, W04415, https:// doi.org/10.1029/2008WR007069.

Narita, K., T. Sekine, and T. Tokuoka, 1984: Thermal properties of urban surface materials-Study on heat balance at asphalt pavement. Geogr. Rev. Japan, 57, 639-651, https://doi.org/ 10.4157/grj1984a.57.9_639.

Nie, W., B. F. Zaitchik, G. Ni, and T. Sun, 2017: Impacts of anthropogenic heat on summertime rainfall in Beijing. J. Hydrometeor., 18, 693-712, https://doi.org/10.1175/ JHM-D-16-0173.1.

Novak, M. D., 1981: The moisture and thermal regimes of a bare soil in the lower Fraser valley during spring. Ph. D. dissertation, University of British Columbia, $175 \mathrm{pp}$.

Ogink-Hendriks, M. J., 1995: Modelling surface conductance and transpiration of an oak forest in the Netherlands. Agric. For. Meteor., 74, 99-118, https://doi.org/10.1016/0168-1923(94) 02180-R.

Oke, T. R., 1988: The urban energy balance. Prog. Phys. Geogr., 12, 471-508, https://doi.org/10.1177/030913338801200401.

Oleson, K. W., G. B. Bonan, J. Feddema, M. Vertenstein, and C. S. B. Grimmond, 2008: An urban parameterization for a global climate model. Part I: Formulation and evaluation or two cities. J. Appl. Meteor. Climatol., 47, 1038-1060, https:// doi.org/10.1175/2007JAMC1597.1.

Rafael, S., H. Martins, M. Marta-Almeida, E. Sa, S. Coelho, A. Rocha, C. Borrego, and M. Lopes, 2017: Quantification and mapping of urban fluxes under climate change: Application of WRF-SUEWS model to Greater Porto area (Portugal). Environ. Res., 155, 321334, https://doi.org/10.1016/j.envres.2017.02.033.

Ragab, R., J. Bromley, P. Rosier, J. D. Cooper, and J. H. C. Gash, 2003: Experimental study of water fluxes in a residential area: 1. Rainfall, roof runoff and evaporation: The effect of slope and aspect. Hydrol. Processes, 17, 2409-2422, https://doi.org/ 10.1002/hyp.1250.

Roberts, S. M., T. R. Oke, C. S. B. Grimmond, and J. A. Voogt, 2006: Comparison of four methods to estimate urban heat storage. J. Appl. Meteor. Climatol., 45, 1766-1781, https:// doi.org/10.1175/JAM2432.1.

Roth, M., C. Jansson, and E. Velasco, 2017: Multi-year energy balance and carbon dioxide fluxes over a residential neighbourhood in a tropical city. Int. J. Climatol., 37, 2679-2698, https://doi.org/10.1002/joc.4873.

Sailor, D. J., 2011: A review of methods for estimating anthropogenic heat and moisture emissions in the urban environment. Int. J. Climatol., 31, 189-199, https://doi.org/10.1002/joc.2106. , and L. Lu, 2004: A top-down methodology for developing diurnal and seasonal anthropogenic heating profiles for urban areas. Atmos. Environ., 38, 2737-2748, https://doi.org/10.1016/ j.atmosenv.2004.01.034.

— sumption data to account for variability in local weather. Environ. Modell. Software, 21, 733-738, https://doi.org/10.1016/ j.envsoft.2005.08.001.

—_, M. Georgescu, J. M. Milne, and M. A. Hart, 2015: Development of a national anthropogenic heating database with an extrapolation for international cities. Atmos. Environ., 118, 7-18, https://doi.org/10.1016/j.atmosenv.2015.07.016.

Salamanca, F., M. Georgescu, A. Mahalov, M. Moustaoui, and M. Wang, 2014: Anthropogenic heating of the urban environment due to air conditioning. J. Geophys. Res. Atmos., 119, 5949-5965, https://doi.org/10.1002/2013JD021225.
Shanghai Municipal Statistics Bureau, 2016: Shanghai Statistical Year Book 2016. China Statistics Press, 473 pp., http://www. stats-sh.gov.cn/html/sjfb/201701/1000339.html.

Shanghai Municipal Statistics Bureau of Xuhui District, 2013: Statistical year book of Xuhui District. http://sis.xh.sh.cn/ login.action.

Shi, Y., X. Gao, Y. Xu, F. Giorgi, and D. Chen, 2016: Effects of climate change on heating and cooling degree days and potential energy demand in the household sector of China. Climate Res., 67, 135-149, https://doi.org/10.3354/cr01360.

South, C., C. S. B. Grimmond, and C. P. Wolfe, 1998: Evapotranspiration rates from wetlands with different disturbance histories: Indiana Dunes National Lakeshore. Wetlands, 18, 216-229, https://doi.org/10.1007/BF03161657.

Stewart, I. D., and T. R. Oke, 2012: Local climate zones for urban temperature studies. Bull. Amer. Meteor. Soc., 93, 1879-1900, https://doi.org/10.1175/BAMS-D-11-00019.1.

— human and animal populations in cities. Int. J. Biometeor., 61, 1159-1171, https://doi.org/10.1007/s00484-016-1296-7.

Stewart, J. B., 1988: Modelling surface conductance of pine forest. Agric. For. Meteor., 43, 19-35, https://doi.org/10.1016/01681923(88)90003-2.

Su, Z., X. Zhi, J. Bian, R. Li, and J. Sun, 2014: Research on the influence of precipitation on traffic characteristics of urban expressway in Shanghai (in Chinese). Atmos. Sci. Res. Appl., 1, 68-76.

Sun, T., E. Bou-Zeid, and G. Ni, 2014: To irrigate or not to irrigate: Analysis of green roof performance via a vertically-resolved hygrothermal model. Build. Environ., 73, 127-137, https:// doi.org/10.1016/j.buildenv.2013.12.004.

_ Z Z. H. Wang, W. Oechel, and C. S. B. Grimmond, 2017: The analytical objective hysteresis model (AnOHM v1.0): Methodology to determine bulk storage heat flux coefficients. Geosci. Model Dev., 10, 2875-2890, https://doi.org/10.5194/ gmd-10-2875-2017.

Takane, Y., and Coauthors, 2017: A climatological validation of urban air temperature and electricity demand simulated by a regional climate model coupled with an urban canopy model and a building energy model in an Asian megacity. Int. J. Climatol., 37, 1035-1052, https://doi.org/10.1002/joc.5056.

Tang, Y. Q., J. G. Tan, C. S. B. Grimmond, Y. Chang, and X. Ao, 2016: Estimation and analysis of aerodynamic parameters for a typical large city (in Chinese). J. Trop. Meteor., 3, 503-514.

United Nations, 2017: World Population Prospects: The 2017 Revision, Key Findings and Advance Tables. Working Paper ESA/P/WP.227, http://esa.un.org/unpd/wpp/Documentation/ pdf/WPP2012_\%20KEY\%20FINDINGS.pdf.

Vahmani, P., and T. S. Hogue, 2014: Incorporating an urban irrigation module into the Noah land surface model coupled with an urban canopy model. J. Hydrometeor., 15, 1440-1456, https://doi.org/10.1175/JHM-D-13-0121.1.

— , and —_, 2015: Urban irrigation effects on WRF-UCM summertime forecast skill over the Los Angeles metropoli$\tan$ area. J. Geophys. Res. Atmos., 120, 9869-9881, https:// doi.org/10.1002/2015JD023239.

Wang, X., J. Liao, J. Zhang, C. Shen, W. Chen, B. Xia, and T. Wang, 2014: A numeric study of regional climate change induced by urban expansion in Pearl River Delta, China. J. Appl. Meteor. Climatol., 53, 346-362, https://doi.org/ 10.1175/JAMC-D-13-054.1.

Wang, X. M., X. Sun, J. Tang, and X. Yang, 2015: Urbanizationinduced regional warming in Yangtze River Delta: Potential 
role of anthropogenic heat release. Int. J. Climatol., 35, 44174430, https://doi.org/10.1002/joc.4296.

Ward, H. C., and C. S. B. Grimmond, 2017: Assessing the impact of changes in surface cover, human behaviour and climate on energy partitioning across Greater London. Landscape Urban Plann., 165, 142-161, https://doi.org/10.1016/ j.landurbplan.2017.04.001.

_ - S. Kotthaus, L. Järvi, and C. S. B. Grimmond, 2016: Surface urban energy and water balance scheme (SUEWS): Development and evaluation at two UK sites. Urban Climate, 18, 1-32, https://doi.org/10.1016/j.uclim.2016.05.001.

—, L. Järvi, T. Sun, S. Onomura, F. Lindberg, A. Gabey, and C. S. B. Grimmond, 2017: SUEWS manual: Version 2017b. University of Reading, 75 pp., http://urban-climate.net/umep/ SUEWS.

Wu, K., and X.-Q. Yang, 2013: Urbanization and heterogeneous surface warming in Eastern China. Chin. Sci. Bull., 58, 13631373, https://doi.org/10.1007/s11434-012-5627-8.

Xu, J., L. Chang, Y. Qu, F. Yan, F. Wang, and Q. Fu, 2016: The meteorological modulation on PM2.5 interannual oscillation during 2013 to 2015 in Shanghai, China. Sci. Total Environ., 572, 1138-1149, https://doi.org/10.1016/j.scitotenv.2016.08.024.

Yang, J., Z.-H. Wang, F. Chen, S. Miao, M. Tewari, J. A. Voogt, and S. Myint, 2015: Enhancing hydrologic modelling in the coupled Weather Research and Forecasting-urban modelling system. Bound.-Layer Meteor., 155, 87-109, https://doi.org/ 10.1007/s10546-014-9991-6.

Yang, X., L. R. Leung, N. Zhao, C. Zhao, Y. Qian, K. Hu, X. Liu, and B. Chen, 2017: Contribution of urbanization to the increase of extreme heat events in an urban agglomeration in east China. Geophys. Res. Lett., 44, 6940-6950, https://doi.org/ 10.1002/2017GL074084.
Yu, J., and J. Wen, 2016: Multi-criteria satisfaction assessment of the spatial distribution of urban emergency shelters based on high-precision population estimation. Int. J. Disaster Risk Sci., 7, 413-429, https://doi.org/10.1007/s13753-016-0111-8.

Zhang, N., Z. Gao, X. Wang, and Y. Chen, 2010: Modeling the impact of urbanization on the local and regional climate in Yangtze River Delta, China. Theor. Appl. Climatol., 102, 331342, https://doi.org/10.1007/s00704-010-0263-1.

_ - X. Wang, Y. Chen, W. Dai, and X. Wang, 2016: Numerical simulations on influence of urban land cover expansion and anthropogenic heat release on urban meteorological environment in Pearl River Delta. Theor. Appl. Climatol., 126, 469-479, https://doi.org/10.1007/s00704-015-1601-0.

Zhao, H., 2007: The study on the sustainable urban transportation mode: The case study of Shanghai. M.S. dissertation, Dept. of Public Administration, East China Normal University, 65 pp.

Zhong, S., Y. Qian, C. Zhao, R. Leung, and X.-Q. Yang, 2015: A case study of urbanization impact on summer precipitation in the Greater Beijing Metropolitan Area: Urban heat island versus aerosol effects. J. Geophys. Res. Atmos., 120, 10903 10 914, https://doi.org/10.1002/2015JD023753.

— , and Coauthors, 2017: Urbanization-induced urban heat island and aerosol effects on climate extremes in the Yangtze River Delta region of China. Atmos. Chem. Phys., 17, 54395457, https://doi.org/10.5194/acp-17-5439-2017.

Zhong, W., D. Wang, D. Xie, and L. Yan, 2017: Dynamic characteristics of Shanghai's population distribution using cell phone signaling data (in Chinese). Geogr. Res., 36, 972-984.

Zou, J., B. Zhou, and J. Sun, 2017: Impact of eddy characteristics on turbulent heat and momentum fluxes in the urban roughness sublayer. Bound.-Layer Meteor., 164, 39-62, https://doi.org/ 10.1007/s10546-017-0244-3. 